\title{
A New Degassing Model to Infer Magma Dynamics from Radioactive Disequilibria in Volcanic Plumes
}

\author{
Luca Terray ${ }^{1,2, *}$, Pierre-J. Gauthier ${ }^{1}$, Giuseppe Salerno ${ }^{3}$ (D), Tommaso Caltabiano ${ }^{3}$ (D), \\ Alessandro La Spina ${ }^{3}$, Pasquale Sellitto ${ }^{4}$ and Pierre Briole ${ }^{5}$ \\ 1 Laboratoire Magmas et Volcans, CNRS, IRD, OPGC, Université Clermont Auvergne, \\ F-63000 Clermont-Ferrand, France; p.j.gauthier@opgc.fr \\ 2 Département de Géosciences, École Normale Supérieure, PSL Research University, 75005 Paris, France \\ 3 Istituto Nazionale di Geofisica e Vulcanologia, Sezione di Catania, Osservatorio Etneo, 95125 Catania, Italy; \\ giuseppe.salerno@ingv.it (G.S.); tommaso.caltabiano@ingv.it (T.C.); alessandro.laspina@ingv.it (A.L.S.) \\ 4 Laboratoire de Météorologie Dynamique, CNRS-UMR8539, École Normale Supérieure, PSL Research \\ University, 75005 Paris, France; psellitto@lmd.ens.fr \\ 5 Laboratoire de Géologie, CNRS-UMR8538, École Normale Supérieure, PSL Research University, \\ 75005 Paris, France; briole@ens.fr \\ * Correspondence: luca.terray@uca.fr or terray@phare.normalesup.org
}

Received: 15 November 2017; Accepted: 14 January 2018; Published: 18 January 2018

\begin{abstract}
Mount Etna volcano (Sicily, Italy) is the place where short-lived radioactive disequilibrium measurements in volcanic gases were initiated more than 40 years ago. Almost two decades after the last measurements in Mount Etna plume, we carried out in 2015 a new survey of ${ }^{210} \mathrm{~Pb}^{210} \mathrm{Bi}^{210} \mathrm{Po}$ radioactive disequilibria in gaseous emanations from the volcano. These new results $\left[\left({ }^{210} \mathrm{Po} /{ }^{210} \mathrm{~Pb}\right)=\right.$ 42 and $\left({ }^{210} \mathrm{Bi} /{ }^{210} \mathrm{~Pb}\right)=7.5$ ] are in fair agreement with those previously reported. Previously published degassing models fail to explain satisfactorily measured activity ratios. We present here a new degassing model, which accounts for ${ }^{222} \mathrm{Rn}$ enrichment in volcanic gases and its subsequent decay into ${ }^{210} \mathrm{~Pb}$ within gas bubbles en route to the surface. Theoretical short-lived radioactive disequilibria in volcanic gases predicted by this new model differ from those produced by the former models and better match the values we measured in the plume during the 2015 campaign. A Monte Carlo-like simulation based on variable parameters characterising the degassing process (magma residence time in the degassing reservoir, gas transfer time, $\mathrm{Rn}$ - $\mathrm{Pb}$-Bi-Po volatilities, magma volatile content) suggests that short-lived disequilibria in volcanic gases may be of use to infer both magma dynamics and degassing kinetics beneath Mount Etna, and in general at basaltic volcanoes. However, this simulation emphasizes the need for accurately determined input parameters in order to produce unambiguous results, allowing sharp characterisation of degassing processes.
\end{abstract}

Keywords: radioactive disequilibria ${ }^{210} \mathrm{~Pb}^{210} \mathrm{Bi}^{-210} \mathrm{Po}$; volcanic gases; degassing processes; geochemical modelling; Mount Etna

\section{Introduction}

Many active basaltic open-conduit volcanoes emit a persistent gas plume, even during quiescence stages without eruptive activity at the surface. This behaviour provides evidence for ongoing magma degassing beneath volcanic centers. Degassing budgets at such active volcanoes may be inferred from both long time-series of $\mathrm{SO}_{2}$ flux measurements [1] and analysis of the sulfur content preserved in melt inclusions [2]. At subduction-zone-related volcanoes, the amount of degassing magma usually exceeds by one or several orders of magnitude the volume of lava actually erupting during the same period [3], which is notably the case of Mount Etna [4]. Moreover, the budget of magma entering the Mount Etna plumbing system, inferred from gravity changes and deformation data, matches the 
volume of degassing magma and exceeds by far the erupted lava volume [5]. It thus emphasizes the fact that degassing and actually erupted volumes of magma can be significantly unbalanced, a feature that is not observed at non-subduction-related volcanoes $[3,6]$. This feature also appears to depend on the eruptive style over a given temporal window [7]. At a volcano like Mount Etna (subduction-zone-related stratovolcano fed with volatile-rich-alkali basalts, e.g., [8]), it could be explained by a dynamic regime of magma redistribution beneath the volcano during which degassed magma is continuously removed by convection from the degassing reservoir and replaced by fresh undegassed magma [9-11].

This observation raises questions about the geometry and dynamic properties of degassing magma reservoirs, which remains poorly known and might have a strong control on eruptive activity $[12,13]$. For instance, high gas fluxes could be explained by the degassing of either large volumes of deep stagnant magma ( $>1 \mathrm{~km}^{3}$ stored at a few kilometres depth) or else small batches $\left(10^{5}-10^{6} \mathrm{~m}^{3}\right)$ of quickly overturned magma brought at shallow levels (hundreds of meter). It is thus of primary importance to set constraints on the characteristic timescales of both magma degassing and gas phase transfer from the degassing reservoir to the surface active craters.

The study of radioactive disequilibria in volcanic gases has proved relevant in constraining magmatic degassing dynamics $[14,15]$. This method focuses on the three last radionuclides of the ${ }^{238} \mathrm{U}$ decay chain: ${ }^{210} \mathrm{~Pb},{ }^{210} \mathrm{Bi}$ and ${ }^{210} \mathrm{Po}$ (see Figure 1). Because they all have short half-lives (22 years, 5 days and 138 days, respectively), these isotopes are suitable to study recent fractionations (younger than two years based on ${ }^{210} \mathrm{Po}$ half-life, the longest-lived ${ }^{210} \mathrm{~Pb}$ decay product) associated with pre-eruptive and syn-eruptive magmatic processes. Furthermore, lead, bismuth and polonium are strongly fractionated upon degassing (polonium being more volatile than bismuth, which is in turn more volatile than lead), which gives birth to large radioactive disequilibria between ${ }^{210} \mathrm{~Pb}^{210} \mathrm{Bi}^{-}{ }^{210} \mathrm{Po}$ in the gas phase $[14,16,17]$. These properties have enabled radioactive disequilibrium measurements in volcanic plumes to be linked to degassing activity through the use of two models. Lambert et al. [14] first developed a static degassing model for which radionuclide exsolution takes place in a degassing cell containing a proportion $\mu$ of deep undegassed magma in radioactive equilibrium. They also considered the transfer time of radionuclides between the time of exsolution from the magma and the time of emission at the surface, as ${ }^{210} \mathrm{Bi}$ (five days half-life) is short-lived enough to significantly decay during gas transfer towards the surface. This approach has been extensively used to characterise gaseous emissions at Mount Etna [14,18,19]. More recently, Gauthier et al. [15] proposed a dynamic degassing model for which radioactive disequilibria in the gas phase also depend on the magma residence time in the degassing reservoir because of continuous regeneration of highly volatile ${ }^{210} \mathrm{Po}$ by decay of its less volatile parent $\left({ }^{210} \mathrm{Bi}\right)$ within the reservoir. This latter model has been successfully applied to persistently degassing, open-conduit, basaltic volcanoes like Stromboli [15] or Ambrym [20]. At these two volcanoes, both the magma residence time in the degassing reservoir and the transfer time of the gas phase towards the surface were estimated and were shown to vary according to eruptive activity.

Almost two decades after the last radioactivity survey in Mount Etna gaseous emissions [19], we went back to Mount Etna in 2015 in order to investigate radioactive disequilibria in the plume. The new measurements presented in this paper have benefited from recent methodological and analytical improvements [21], and they are in fair agreement with previously published data ([19], and references therein). Based on the concept of the previous dynamic degassing model [15], a new theoretical framework for the degassing of radionuclides is presented here. We show that the very short-lived radon isotope ${ }^{222} \mathrm{Rn}$ can be significantly enriched in the gas phase when magma residence time in the degassing reservoir increases. Although it has been neglected so far, mostly because of its short half-life of 3.8 days, we show that ${ }^{222} \mathrm{Rn}$ plays a major role in controlling the magnitude of ${ }^{210} \mathrm{~Pb}^{-210} \mathrm{Bi}^{210} \mathrm{Po}$ disequilibria by producing, through its radioactive decay, a new generation of ${ }^{210} \mathrm{~Pb}$ atoms within gas bubbles. By using a dataset of previously published values describing both trace element volatilities and volatile content in magmas from Etna, we present a Monte Carlo-like simulation 
that explains radioactive disequilibria measured in 2015 in Mount Etna gases well. Implications for the retrieval of quantitative information on degassing dynamics from radioactive disequilibria in a volcanic plume are presented at the end of the paper.

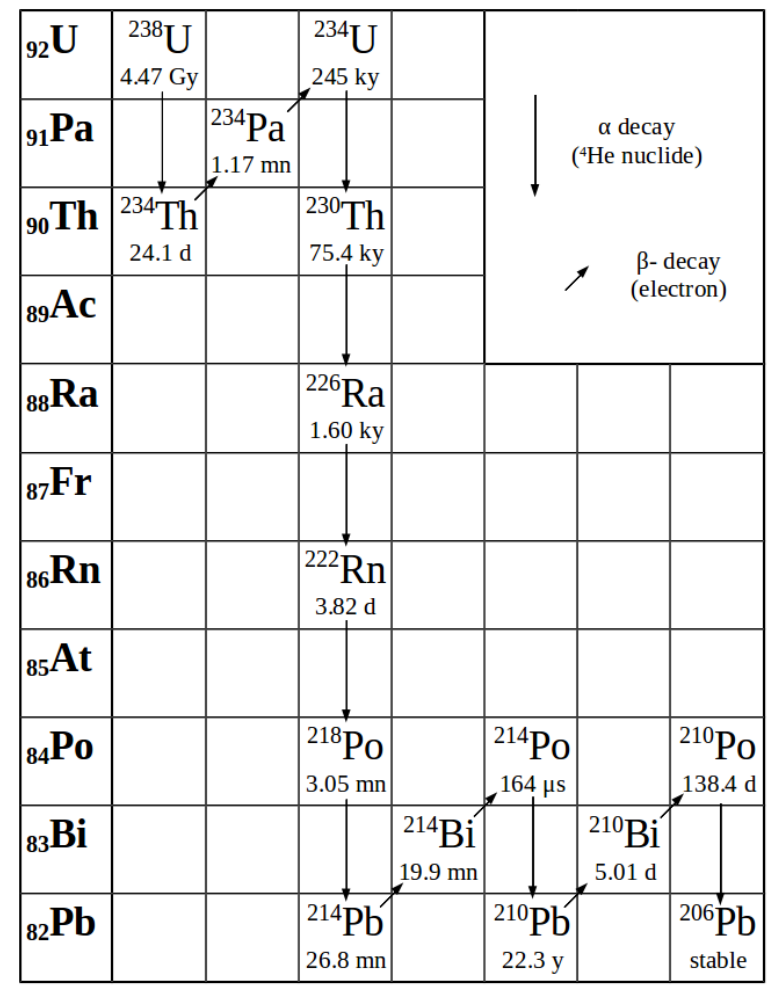

Figure 1. ${ }^{238} \mathrm{U}$ decay chain. Half-lives are indicated beneath the symbol of the element. Minor embranchments are not reproduced.

\section{Short-Lived Radioactivity Measurements in Mount Etna Plume}

\subsection{Field Description and Sampling Techniques}

Mount Etna, one of the most active volcanoes worldwide, is an easily accessible volcano with a persistent degassing activity, making it a strong gas emitter. It has been the focus of many studies aiming at surveying short-lived disequilibria in volcanic gases [14,16,18,19,22,23]. During these two decades of regular survey at the end of the 20th century, the Mount Etna summit area was quite different than it is today. At that time, the volcano had only four summit craters (northeast Crater (NEC), Voragine (VOR), Bocca Nuova (BN) and the late-born southeast Crater (SEC); Figure 2). Since 2001, Mount Etna has erupted frequently, almost on a yearly basis, producing large lava flows and powerful paroxysmal events associated with lava fountaining episodes that significantly remodeled the summit area and ultimately gave birth to the New South-East Crater (NSEC, see Figure 2) [24]. In May 2015, we carried out a new survey of ${ }^{210} \mathrm{~Pb}-{ }^{210} \mathrm{Bi}^{210} \mathrm{Po}$ radioactive disequilibria in the volcanic plume. The field campaign took place during a brief, 5-day-long eruption at NSEC. After several days of tremor increase, eruptive activity started at NSEC on 12 May 2015 with loud explosions producing reddish to dark grey ash-rich plumes, followed by sustained strombolian activity at NSEC summit while a fissure opened on the eastern flank of the cone, emitting a lava flow that travelled towards and inside Valle del Bove. On 15 May, the intensity of the eruption gradually decreased until it reached an end on 16 May. The eruptive activity at NSEC during this short eruptive episode was too intense to grant safe access to the summit. We collected the diluted plume of Mount Etna downwind of the crater on the southern slope of the volcano, at remote sites near Torre del Filosofo (Figure 2). Samples 
collected at these locations were mostly from the main ash-rich gas plume emitted by the NSEC summit, although a minor contribution of the small gas plume released from the eruptive fissure cannot be ruled out.

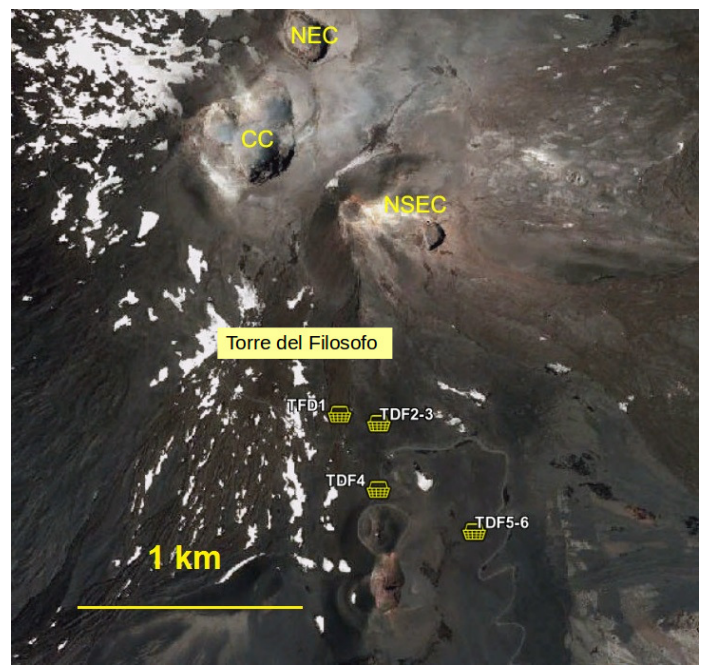

Figure 2. Map of Mount Etna summital zone in 2012 (aerial photography from Italian Geoportal). CC stands for Central Craters (Voragine and Bocca Nuova), NEC for northeast Crater and NSEC for new southeast Crater. Sampling sites (TDF1, TDF2-3, TDF4 and TDF5-6, where TDF stands for Torre del Filosofo) are pointed on the map.

The three investigated radionuclides are engaged in chemical compounds (mostly halides and sulfates) that are gaseous at magma temperature but are quenched into solid particles once in the cold atmosphere. They are consequently born in the aerosol fraction of the gas plume and can be easily sampled by filtration of the diluted plume through a membrane. For this study, we used high flowrate pumps (110 L/min) fed by a 12V-35Ah battery and connected to a home-designed polyvinyl chloride (PVC) filter-holder (exposition diameter of $50 \mathrm{~mm}$ ) containing a single cellulose acetate filter (Poelmann-Schneider blue type, $0.2 \mu \mathrm{m}$ mean porosity). Sampling times ranged between $15 \mathrm{~min}$ and $1 \mathrm{~h}$ (corresponding to a volume of filtrated air in the range $1.7-6.6 \mathrm{~m}^{3}$, Table 1) to ensure that enough diluted plume passed through the filters so that radionuclide activities on filter samples can be analysed.

Table 1. ${ }^{210} \mathrm{~Pb}^{210} \mathrm{Bi}^{210} \mathrm{Po}$ radioactivity in Mount Etna plume. Sample names correspond to sampling sites as described in Figure 2. Activities are reported in $\mathrm{mBq} / \mathrm{m}^{3}$ with $1-\sigma$ uncertainties. "bdl" stands for below detection limit. Sampling starting time is expressed in local time.

\begin{tabular}{cccccc}
\hline Sample & Date and time & Volume $\mathbf{( m}^{\mathbf{3}} \mathbf{)}$ & ${ }^{\mathbf{2 1 0}} \mathbf{P b}$ & ${ }^{\mathbf{2 1 0}} \mathbf{B i}$ & ${ }^{{ }^{\mathbf{1 1 0}} \mathbf{P o}}$ \\
\hline Atmospheric blank & $11 / 05 / 201512: 00$ & 3.9 & bdl & bdl & bdl \\
TDF1 & $12 / 05 / 201512: 07$ & 3.9 & bdl & bdl & bdl \\
TDF2 & $13 / 05 / 201511: 04$ & 6.6 & $0.8 \pm 0.2$ & $3.1 \pm 1$ & $14.6 \pm 0.7$ \\
TDF3 & $13 / 05 / 201512: 15$ & 6.6 & bdl & bdl & bdl \\
TDF4 & $14 / 05 / 201510: 51$ & 1.7 & $3.5 \pm 1.0$ & $29 \pm 5$ & $212 \pm 3$ \\
TDF5A & $14 / 05 / 201511: 38$ & 3.9 & $4.0 \pm 0.4$ & $31 \pm 3$ & $162 \pm 2$ \\
TDF5B & $14 / 05 / 201511: 38$ & 3.0 & $8.2 \pm 0.4$ & $62 \pm 2$ & $349 \pm 2$ \\
TDF6 & $14 / 05 / 201512: 31$ & 6.6 & $5.9 \pm 0.2$ & $41 \pm 2$ & $217 \pm 1$ \\
\hline
\end{tabular}

\subsection{Analytical Techniques}

Because ${ }^{210} \mathrm{Bi}$ (5.01 days half-life) thoroughly decays away in about one month, filter samples were taken back to Laboratoire Magmas et Volcans in Clermont-Ferrand within a few days after 
collection. Untreated filters were analysed with a low-background noise alpha-beta counting unit (IN20 Canberra) following the procedure described in Gauthier et al. [21]. Repeated measurements were carried on over a month after collection in the field, each analytical cycle lasting $48 \mathrm{~h}$ (one cycle comprises eight 6-hour-long counting blocks that are ultimately averaged, the mean activity being considered as the "instantaneous" activity at the time $t_{i}+24 \mathrm{~h}$, where $t_{i}$ is the starting date and time of a given cycle). Both alpha and beta activities were simultaneously determined on filter samples. Alpha counts provide a direct measure of ${ }^{210} \mathrm{Po}$ activity while beta counts correspond to the detection of ${ }^{210} \mathrm{Bi}$ beta decay particles. Beta emissions of ${ }^{210} \mathrm{~Pb}$ cannot be directly measured because of their energies that are too low, so that ${ }^{210} \mathrm{~Pb}$ is measured via ${ }^{210} \mathrm{Bi}$ one month after sampling when both isotopes have reached radioactive equilibrium [21]. Radionuclide activities on filter samples were determined by subtracting the detector background (electronic noise and some unblocked cosmic rays) and by taking into account the detector efficiency and an attenuation factor for alpha particles [25]. Initial activities at the time of sampling were then retrieved by fitting radioactive decay trend during the one-month period of analysis by using classical radioactivity laws.

\subsection{Analytical Results}

Analytical results are reported in Table 1 along with 1- $\sigma$ uncertainties based on the counting statistics. Uncertainties deriving from the variability of the volume of sampled plume are not propagated since they are quite difficult to estimate while working in the field. However, the three radionuclides are sampled and measured on the same filter and, hence, this uncertainty does not impact radionuclide ratios (i.e., radioactive disequilibria). In addition to volcanic aerosol samples, a sample of the atmospheric background at Mount Etna was collected in clear sky conditions, outside of the plume influence, close to the Sapienza touristic area. As expected, activities in the atmospheric background are below the detection limit for the three radionuclides. Considering the volume of atmosphere sampled for the blank, and the minimum detectable activity (depending on the duration of a counting cycle and on the instrument background noise) in both alpha and beta modes with the IN20 counter, both ${ }^{210} \mathrm{~Pb}$ and ${ }^{210} \mathrm{Bi}$ detection limit can be quantified at $0.8 \mathrm{mBq} / \mathrm{m}^{3}$ and that of ${ }^{210} \mathrm{Po}$ at $0.3 \mathrm{mBq} / \mathrm{m}^{3}$. Although activities are below detection limits for samples TDF1 and TDF3, and similar to the bêta detection limit for sample TDF2, all other samples appear significantly enriched in ${ }^{210} \mathrm{~Pb}$, ${ }^{210} \mathrm{Bi}$ and ${ }^{210}$ Po compared to the atmospheric blank. As previously shown ([19], and references therein), this suggests that the plume of Mount Etna is considerably enriched in radionuclides over a standard atmosphere and that high-quality samples can be obtained at safe distances from the summit area. Figure 3 shows ${ }^{210} \mathrm{Bi}$ (Figure $3 \mathrm{a}$ ) and ${ }^{210} \mathrm{Po}$ (Figure $3 \mathrm{~b}$ ) activities plotted against ${ }^{210} \mathrm{~Pb}$ activities for all aerosol samples. Activities follow linear trends passing through the origin, which are interpreted as dilution trends of the volcanic gas (considerably enriched in ${ }^{210} \mathrm{~Pb},{ }^{210} \mathrm{Bi}$ and ${ }^{210} \mathrm{Po}$ ) into the atmosphere for which radionuclide activities are negligible. The two linear correlations in Figure 3 are well defined $\left(R^{2}=0.99\right.$ for ${ }^{210} \mathrm{Bi}$ vs. ${ }^{210} \mathrm{~Pb} ; R^{2}=0.91$ for ${ }^{210} \mathrm{Po}$ vs. $\left.{ }^{210} \mathrm{~Pb}\right)$, which suggests that the dilution of volcanic gases in the atmosphere does not significantly affect their pristine isotopic signature within at least $1.5 \mathrm{~km}$ distance from the summit area. Furthermore, it was reported that radioactive disequilibria in gases released at summit craters significantly differ from those in gas emanations from eruptive vents along eruptive fissures [19]. Therefore, the well-defined linear correlations observed in Figure 3 suggest that the contribution of gases released at the eruptive fissure to the main plume is negligible or alternatively steady through time, which would be highly fortuitous. Samples collected in the diluted plume are thus taken to be representative of the chemistry of volcanic gases at the source. Radioactive disequilibria in the volcanic plume of the NSEC are retrieved by linear regression of the whole dataset at $\left({ }^{210} \mathrm{Bi} /{ }^{210} \mathrm{~Pb}\right)=7.5 \pm 0.4$ and $\left({ }^{210} \mathrm{Po} /{ }^{210} \mathrm{~Pb}\right)=42 \pm 6$. These values are in fair agreement with those previously reported for Mount Etna's summit craters, in the range $10-30$ for $\left({ }^{210} \mathrm{Bi} /{ }^{210} \mathrm{~Pb}\right)$ and between 20 and up to 90 for $\left({ }^{210} \mathrm{Po} /{ }^{210} \mathrm{~Pb}\right)([19]$, and references therein). 

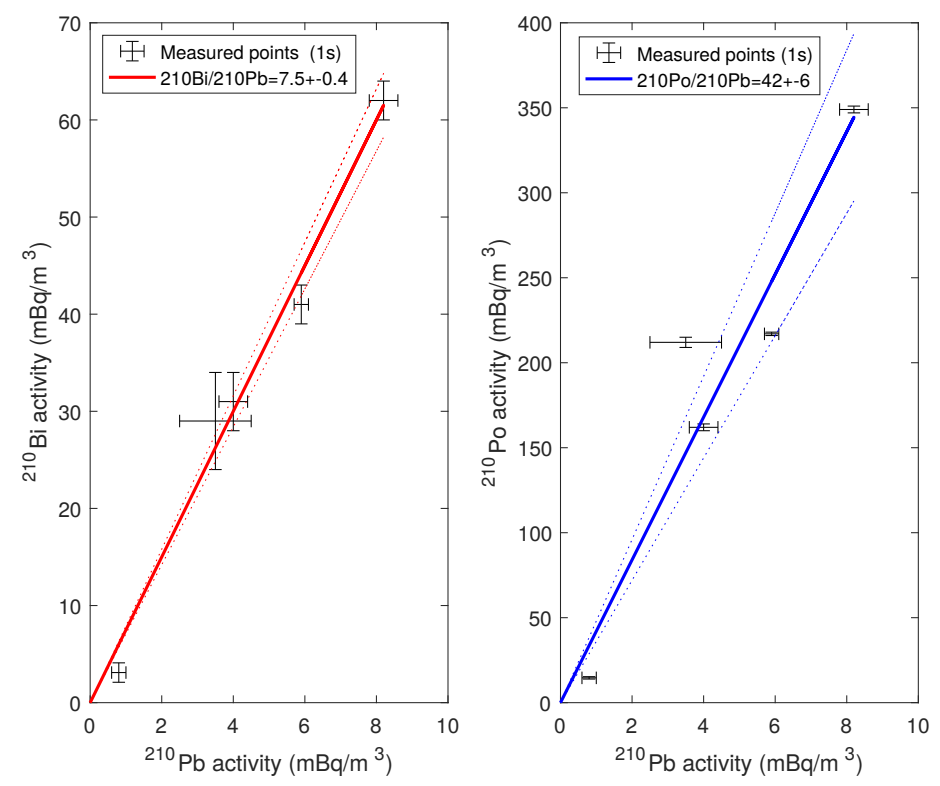

Figure 3. Volumic activities in the plume. Bars represent one sigma errors and are derived from the uncertainty of radioactivity analysis. Full lines represent the linear regression between the points and the origin, and dotted lines represent two sigma standard error on the slope of the regression trend.

\section{Modelling of Radionuclide Degassing and ${ }^{210} \mathrm{~Pb}^{210} \mathrm{Bi}^{210} \mathrm{Po}$ Radioactive Disequilibria in Volcanic Plumes}

Lambert et al. [14] and then Gauthier et al. [15] linked ${ }^{210} \mathrm{~Pb}^{210} \mathrm{Bi}^{210} \mathrm{Po}$ radioactive disequilibria in volcanic gases to degassing processes. Although radioactive disequilibria in volcanic gases from Mount Etna have been successfully explained by the model of Lambert et al. [14], Gauthier et al. [15] showed that Lambert's model can be used only if the magmatic vapour is released from a rapidly overturned batch of deep magma in radioactive equilibrium prior to degassing. This is due to the fact that the model proposed by Lambert et al. [14] neglects, in the degassing magma, the radioactive ingrowth of ${ }^{210} \mathrm{Bi}$ and ${ }^{210} \mathrm{Po}$ (both moderately to highly volatile at magma temperature) from their parent ${ }^{210} \mathrm{~Pb}$, which is weakly volatile and mostly remains in the melt. If the magma residence time in the degassing reservoir is long enough for ${ }^{210} \mathrm{~Pb}$ to decay, then both ${ }^{210} \mathrm{Bi}$ and ${ }^{210} \mathrm{Po}$ atoms are regenerated in the melt. The longer is the residence time, the more efficient is the regeneration. Because ${ }^{210} \mathrm{~Pb}$ decay products have greater affinity for the gas phase than for the melt, they preferentially partition into the vapour phase according to their own volatility. When the magma residence time in the degassing reservoir increases, magmatic gases consequently become more and more enriched in the most volatile ${ }^{210} \mathrm{Po}$ and, to a lesser extent, in the moderately volatile ${ }^{210} \mathrm{Bi}$ over ${ }^{210} \mathrm{~Pb}$ [15]. By neglecting radioactive ingrowth within the degassing magma, Lambert et al. [14] considered that the ratio of two radionuclides in the magmatic vapour at the time of exsolution could reach a maximum value equal to the ratio of their emanation coefficients $\epsilon$, the widely used parameter describing trace element volatility [14,26]. Gauthier et al. [15] showed that the $\epsilon$ ratio of two radionuclides corresponds instead to the minimum value for activity ratios in the magmatic vapour at the time of volatile exsolution. This minimum value is reached when magma residence time is negligible compared to ${ }^{210} \mathrm{Po}$ half-life i.e., less than about 10 days. For increasing values of the magma residence time, activity ratios in the gas phase increase up to a theoretical value, which is defined by the ratio of the liquid-gas partition coefficients $\mathrm{D}$ for the considered radionuclides [15].

There is a broad agreement that the emanation coefficient of ${ }^{210} \mathrm{Po}$ for basaltic systems (including Mount Etna) is close to $100 \%$, suggesting that most of polonium atoms are transferred to the magmatic vapour upon degassing [22,27-30]. The emanation coefficient of lead in basaltic systems appears to be 
higher in calk-alkaline systems than in other geodynamical settings [21]. At Mount Etna, like at other arc-related basaltic volcanoes, it has a value of approximately $1.0 \pm 0.5 \%[14,17,31,32]$. Therefore, the minimum value for $\left({ }^{210} \mathrm{Po} /{ }^{210} \mathrm{~Pb}\right)$ activity ratios in Mount Etna gases should be around 100, which has never been measured, excepted at the beginning of the 1992 eruption [19]. In particular, the ratio of $42 \pm 6$ we find in the May 2015 plume is far below this minimum theoretical value and cannot be explained by using the dynamic degassing model with realistic parameters for metal volatility [15]. In order to reproduce our observations, the degassing model would indeed require either polonium emanation coefficients lower than $50 \%$, which is in strong disagreement with analyses of freshly erupted lavas at Mount Etna [22], or else lead emanation coefficients up to 3\% or even more, which has never been reported.

\section{1. ${ }^{222}$ Rn Enrichments in Volcanic Gases: Towards a New Degassing Model for Short-Lived Radionuclides}

Recent studies have suggested that magmas having accumulated an ${ }^{222} \mathrm{Rn}$-rich gas phase may present significant ${ }^{210} \mathrm{~Pb}$ excesses over ${ }^{226} \mathrm{Ra}$ [29,33-36]. Volcanic gases are also characterised, in some cases, by ${ }^{210} \mathrm{~Pb} / \mathrm{Pb}$ ratios significantly higher than those measured in lavas [23]. Although the origin of these ${ }^{210} \mathrm{~Pb}$ enrichments in volcanic gases has not been fully understood, we tentatively assume that ${ }^{210} \mathrm{~Pb}$ excesses could result from radioactive decay of ${ }^{222} \mathrm{Rn}$ atoms in the gas phase.

It is worth noting that, in the previously published degassing models [14,15], the radioactive decay of ${ }^{222} \mathrm{Rn}$ was not taken into account. We present therefore a new degassing model that accounts for it. The conceptual framework of this new model matches that of Gauthier et al. [15]. Accordingly, we consider that volatile exsolution takes place in an open degassing reservoir, which has reached a dynamical and chemical steady-state. Dynamical steady-state implies that the degassing reservoir has a constant mass $M$ (or volume $V$ ) through time. It means that any input flux $\phi_{0}$ of deep undegassed magma (in radioactive equilibrium for ${ }^{222} \mathrm{Rn}$ and its daughters) has to be balanced by a flux of gas $\phi_{G}$ and a flux of lava $\phi_{L}$ leaving the reservoir. Let $\alpha$ be the fraction of volatiles initially dissolved in the deep magma and ultimately released, the fluxes $\phi_{G}$ and $\phi_{L}$ can be written:

$$
\begin{aligned}
& \phi_{G}=\alpha \phi_{0}, \\
& \phi_{L}=(1-\alpha) \phi_{0} .
\end{aligned}
$$

In such a steady-state reservoir, the replenishment rate is given by $\phi_{0} / M$. Its reciprocal, $M / \phi_{0}$, defines the magma residence time $\tau$ in the degassing reservoir. In such reservoir, the number of atoms $N_{k, L}$ of each radioactive isotope $\mathrm{I}_{\mathrm{k}}$ (either ${ }^{222} \mathrm{Rn},{ }^{210} \mathrm{~Pb},{ }^{210} \mathrm{Bi}^{210} \mathrm{Po}, \mathrm{k}$ depending on the position along the decay chain) in the degassing magma varies according to:

$$
\frac{\partial N_{k, L}}{\partial t}=\lambda_{k-1} N_{k-1, L}-\lambda_{k} N_{k, L}+\phi_{0} C_{k, 0}-\phi_{L} C_{k, L}-\phi_{G} C_{k, G}
$$

where $C_{k}$ stands for the mass concentration of $\mathrm{I}_{\mathrm{k}}$ either in the undegassed magma (index 0 ), the degassed lava (index L) or the gas phase (index G), and where $\lambda_{k}$ stands for the radioactive decay constant of $I_{k}$. From left to right, the right terms of Equation (2) correspond to the production of $I_{k}$ by $I_{k-1}$ decay, the loss of $I_{k}$ according to its own decay, the input of $I_{k}$ from the undegassed magma entering the reservoir, the output of $\mathrm{I}_{\mathrm{k}}$ by magma withdrawal and finally the output of $\mathrm{I}_{\mathrm{k}}$ by degassing. This equation can be expressed in terms of activity per unit of mass by multiplying each member by $\lambda_{k} / M$ :

$$
\frac{\partial\left(\mathrm{I}_{\mathrm{k}}\right)_{L}}{\partial t}=\lambda_{k}\left(\mathrm{I}_{\mathrm{k}-1}\right)_{L}-\lambda_{k}\left(\mathrm{I}_{\mathrm{k}}\right)_{L}+\frac{\phi_{0}}{M}\left(\mathrm{I}_{\mathrm{k}}\right)_{0}-(1-\alpha) \frac{\phi_{0}}{M}\left(\mathrm{I}_{\mathrm{k}}\right)_{L}-\alpha \frac{\phi_{0}}{M}\left(\mathrm{I}_{\mathrm{k}}\right)_{G},
$$

where parentheses denote activity per unit of mass, and $\phi_{L}$ and $\phi_{G}$ have been replaced by their expression in Equation (1). With the assumption that the reservoir has also reached a chemical 
steady-state, which is justified for short-lived volatile isotopes [15], Equation (2) is equal to 0. By introducing a liquid gas partitioning coefficient $D_{\mathrm{I}_{\mathrm{K}}}$ such as:

$$
D_{\mathrm{I}_{\mathrm{k}}}=\frac{\left(\mathrm{I}_{\mathrm{k}}\right)_{G}}{\left(\mathrm{I}_{\mathrm{k}}\right)_{L}}
$$

the activity of any radionuclide $I_{k}$ in the gas phase may be obtained from Equation (3) such as:

$$
\left(\mathrm{I}_{\mathrm{k}}\right)_{G}=\frac{\lambda_{k}\left(\mathrm{I}_{\mathrm{k}-1}\right)_{L}+\frac{\left(\mathrm{I}_{\mathrm{k}}\right)_{0}}{\tau}}{\frac{\lambda_{k}}{D_{\mathrm{I}_{\mathrm{k}}}}+\left(\alpha+\frac{1-\alpha}{D_{\mathrm{I} \mathrm{k}}}\right) \frac{1}{\tau}},
$$

Note that both liquid-gas partitioning coefficients $D$ and emanation coefficients $\epsilon$ are linked through the following relationship [15]:

$$
\epsilon_{\mathrm{I}_{\mathrm{k}}}=\left(1+\frac{1-\alpha}{\alpha D_{\mathrm{I}_{\mathrm{k}}}}\right)^{-1}
$$

\subsection{Radioactive Disequilibria in Gases at the Time of Exsolution}

\subsubsection{Specific Case of ${ }^{222} \mathrm{Rn}$ Exsolution}

As shown by Equation (5), the activity of a radionuclide $\mathrm{I}_{\mathrm{k}}$ in the gas phase depends on the activity of its precursor in the decay chain, which means that a precursor for ${ }^{210} \mathrm{~Pb}$ has to be taken into account so as to compute all other activities. All four radionuclides between ${ }^{222} \mathrm{Rn}$ and ${ }^{210} \mathrm{~Pb}\left({ }^{218} \mathrm{Po},{ }^{214} \mathrm{~Pb},{ }^{214} \mathrm{Bi}\right.$ and ${ }^{214} \mathrm{Po}$ ) have half-lives of a few minutes at most (Figure 1), which appears very short compared to the expected residence time of the magma in the degassing reservoir. They can thus be neglected in the model and we consider here, mathematically speaking, that ${ }^{210} \mathrm{~Pb}$ is directly regenerated by ${ }^{222} \mathrm{Rn}$ decay. In order to quantify ${ }^{222} \mathrm{Rn}$ degassing efficiency Gauthier and Condomines [37] introduced a parameter $f$, ranging between 0 (no radon degassed) and 1 (total degassing of radon), and used this previous parameter to calculate ${ }^{222} \mathrm{Rn}$ activity in the degassing melt at steady-state:

$$
\left({ }^{222} \mathrm{Rn}\right)_{L}=(1-f)\left({ }^{226} \mathrm{Ra}\right)_{L}
$$

with

$$
\left({ }^{226} \mathrm{Ra}\right)_{L}=\frac{\left({ }^{226} \mathrm{Ra}\right)_{0}}{1-\alpha},
$$

since radium forms no volatile compounds in basaltic magmas [14]. Applying Equation (3) to the case of ${ }^{222} \mathrm{Rn}$, replacing $\left({ }^{222} \mathrm{Rn}\right)_{L}$ and $\left({ }^{226} \mathrm{Ra}\right)_{L}$ by their expression in Equations (7) and (8), respectively, and $\phi_{0} / M$ by $1 / \tau$, we obtain:

$$
\left({ }^{222} \mathrm{Rn}\right)_{G}=\left({ }^{226} \mathrm{Ra}\right)_{0} \frac{f}{\alpha}\left(1+\frac{\tau \lambda_{\mathrm{Rn}}}{1-\alpha}\right)
$$

Note that, in order to clarify notations, $\lambda_{222}$ Rn is written $\lambda_{\mathrm{Rn}}$, and other radioactivity constants are noted similarly. This relation suggests that significant excesses of ${ }^{222} \mathrm{Rn}$ can be produced in the gas phase for long residence times. Providing that the escape time of gases is long enough (see Section 3.3), ${ }^{222} \mathrm{Rn}$ atoms could then decay and act as a significant additional source of ${ }^{210} \mathrm{~Pb}$ in the gas phase.

\subsection{2. ${ }^{222} \mathrm{Rn}-{ }^{210} \mathrm{~Pb}^{210} \mathrm{Bi}^{210} \mathrm{Po}$ Fractionation upon Exsolution}

${ }^{210} \mathrm{~Pb},{ }^{210} \mathrm{Bi},{ }^{210} \mathrm{Po}$ activities in the gas phase after exsolution can now be derived iteratively using Equation (5). Because short-lived ${ }^{226}$ Ra daughters are thought to be in radioactive equilibrium in 
deep magmas prior to degassing [37], the application of Equation (5) to ${ }^{210} \mathrm{~Pb}$, taking into account the expression of $\left({ }^{222} \mathrm{Rn}\right)_{L}$ given by Equations (7) and (8) leads to:

$$
\left({ }^{210} \mathrm{~Pb}\right)_{G}=A_{0} \frac{\lambda_{\mathrm{Pb}} \frac{1-f}{1-\alpha}+\frac{1}{\tau}}{\frac{\lambda_{\mathrm{Pb}}}{D_{\mathrm{Pb}}}+\left(\alpha+\frac{1-\alpha}{D_{\mathrm{Pb}}}\right) \frac{1}{\tau}},
$$

where $A_{0}$ refers to the equilibrium activity of all nuclides.

The application of Equation (5) to ${ }^{210} \mathrm{Bi}$, replacing $\left({ }^{210} \mathrm{~Pb}\right)_{L}$ by $\left({ }^{210} \mathrm{~Pb}\right)_{G} / D_{\mathrm{Pb}}$ and using the expression of $\left({ }^{210} \mathrm{~Pb}\right)_{G}$ given in Equation (10), leads to an expression of $\left({ }^{210} \mathrm{Bi}\right)_{G}$. This expression is then used to determine $\left({ }^{210} \mathrm{Po}\right)_{G}$, still using Equation (5). The obtained expressions are reproduced in Appendix A and, like Equations (9) and (10), they have the following form:

$$
A_{0} \mathcal{F}\left(\tau, \alpha, D_{\mathrm{Pb}}, D_{\mathrm{Bi}}, D_{\mathrm{Po}}, f\right),
$$

where $\mathcal{F}$ is a function of $\tau, \alpha, f$ and $D_{\mathrm{Pb}}, D_{\mathrm{Bi}}$ and $D_{\mathrm{Po}}$. Therefore, radioactive disequilibria $\left({ }^{222} \mathrm{Rn} /{ }^{210} \mathrm{~Pb}\right),\left({ }^{210} \mathrm{Bi} /{ }^{210} \mathrm{~Pb}\right)$ and $\left({ }^{210} \mathrm{Po} /{ }^{210} \mathrm{~Pb}\right)$ do not depend on the magma initial activity but only on these six parameters.

For instance, dividing Equation (9) by Equation (10), $\left({ }^{222} \mathrm{Rn} /{ }^{210} \mathrm{~Pb}\right)_{\mathrm{G}}$ may be expressed:

$$
\left(\frac{{ }^{222} \mathrm{Rn}}{{ }^{210} \mathrm{~Pb}}\right)_{\mathrm{G}}=\frac{f}{\alpha}\left(1+\frac{\tau \lambda_{\mathrm{Rn}}}{1-\alpha}\right)\left(\frac{\lambda_{\mathrm{Pb}} \frac{1-f}{1-\alpha}+\frac{1}{\tau}}{\frac{\lambda_{\mathrm{Pb}}}{D_{\mathrm{Pb}}}+\left(\alpha+\frac{1-\alpha}{D_{\mathrm{Pb}}}\right) \frac{1}{\tau}}\right)^{-1},
$$

$\left({ }^{210} \mathrm{Bi} /{ }^{210} \mathrm{~Pb}\right)_{G}$ and $\left({ }^{210} \mathrm{Po} /{ }^{210} \mathrm{~Pb}\right)_{G}$ are given by Equations (6) and (9) in Gauthier et al. [15].

\subsection{Gas Phase Transfer towards the Surface: Radioactive Decay within Gas Bubbles}

Activities of each radionuclide in the gas phase after a transfer time $\theta$ are noted $\left(\mathrm{I}_{\mathrm{k}}\right)_{G}^{\theta}$. Assuming that the gas phase behaves as a closed system as far as radionuclides are concerned, the activities after a transfer time $\theta$ can be obtained by solving the following system of coupled equations:

$$
\left\{\begin{array}{l}
\partial\left({ }^{222} \mathrm{Rn}\right)_{G}^{\theta} / \partial \theta=-\lambda_{\mathrm{Rn}}\left({ }^{222} \mathrm{Rn}\right)_{G^{\prime}}^{\theta} \\
\partial\left({ }^{210} \mathrm{~Pb}\right)_{G}^{\theta} / \partial \theta=\lambda_{\mathrm{Pb}}\left({ }^{222} \mathrm{Rn}\right)_{G}^{\theta}-\lambda_{\mathrm{Pb}}\left({ }^{210} \mathrm{~Pb}\right)_{G^{\prime}}^{\theta} \\
\partial\left({ }^{210} \mathrm{Bi}\right)_{G}^{\theta} / \partial \theta=\lambda_{\mathrm{Bi}}\left({ }^{210} \mathrm{~Pb}\right)_{G}^{\theta}-\lambda_{\mathrm{Bi}}\left({ }^{210} \mathrm{Bi}\right)_{G^{\prime}}^{\theta} \\
\partial\left({ }^{210} \mathrm{Po}\right)_{G}^{\theta} / \partial \theta=\lambda_{\mathrm{Po}}\left({ }^{210} \mathrm{Bi}\right)_{G}^{\theta}-\lambda_{\mathrm{Po}}\left({ }^{210} \mathrm{Po}\right)_{G^{\prime}}^{\theta}
\end{array}\right.
$$

with initial conditions $\left(\mathrm{I}_{\mathrm{k}}\right)_{G}^{\theta=0}=\left(\mathrm{I}_{\mathrm{k}}\right)_{G}$, where $\left(\mathrm{I}_{\mathrm{k}}\right)_{G}$ are the expressions established above.

This system has been solved by Bateman [38] in its generalized formulation. The solution has also been formalized in an algebraic way e.g., [39]. This approach is more suitable for a numerical implementation and is thus chosen:

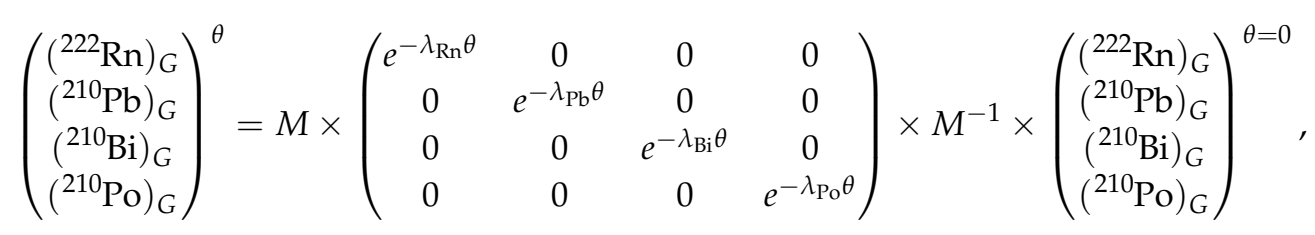

where $M$ and $M^{-1}$ are matrices for which coefficients are only a function of radioactive constants $\lambda_{k}$ and are reproduced in Appendix B (Equations (A3) and (A4)). Because initial conditions have the form described by Equation (11), the solution described by Equation (14) also has the same form. 
Therefore, radioactive disequilibria in the gas phase after a given transfer time do not depend on the initial activity of $\mathrm{I}_{\mathrm{k}}$ in the magma. Their expression are not reproduced here, but they can be explicited replacing $M, M^{-1},\left({ }^{222} \mathrm{Rn}\right)_{G},\left({ }^{210} \mathrm{~Pb}\right)_{G},\left({ }^{210} \mathrm{Bi}\right)_{G}$ and $\left({ }^{210} \mathrm{Po}\right)_{G}$ by their expressions provided before or in the appendix.

\subsection{Results and Discussion}

Radioactive disequilibria between ${ }^{210} \mathrm{~Pb},{ }^{210} \mathrm{Bi}$ and ${ }^{210} \mathrm{Po}$ in the gas phase according to our model are presented in Figure 4. Values of $\alpha, f$ and volatility for $\mathrm{Pb}, \mathrm{Bi}$ and $\mathrm{Po}(D$ or equivalently $\epsilon$ ) are fixed using reasonable estimates from the literature ( $\alpha=5 \mathrm{wt.} \%, f=1, \epsilon_{\mathrm{Pb}}=1.5 \%, \epsilon_{\mathrm{Bi}}=36 \%, \epsilon_{\mathrm{Po}}=100 \%$ ). The choice of these values, and their impact on the model predictions, are discussed later (see Section 4 ). Theoretical values of disequilibria are plotted against the residence time in the degassing reservoir for several values of the transfer time. These new results are systematically compared to radioactive disequilibria produced by the model of Gauthier et al. [15].

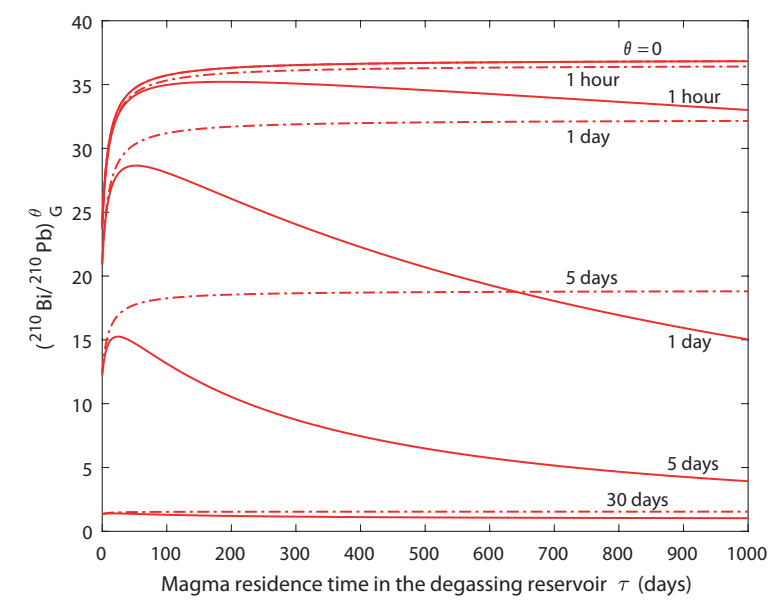

(a)

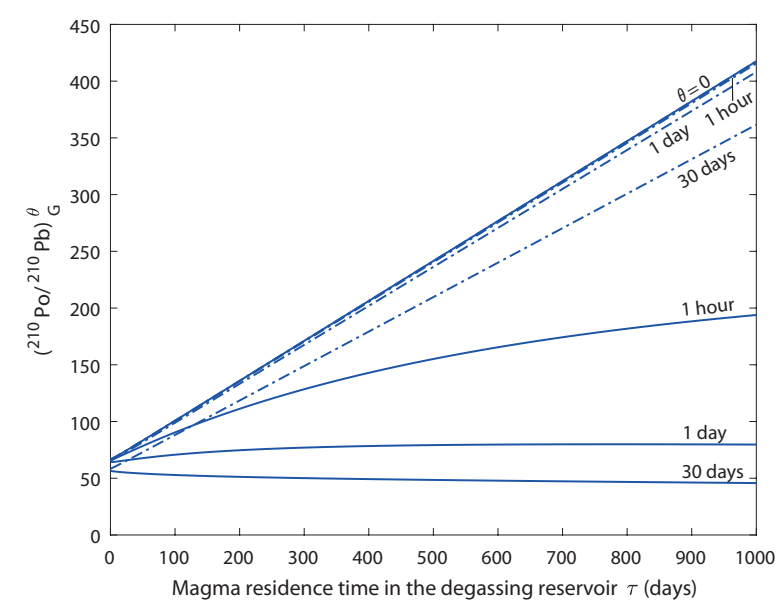

(b)

Figure 4. Radioactive disequilibria $(\mathbf{a})\left({ }^{210} \mathrm{Bi} /{ }^{210} \mathrm{~Pb}\right)$ and $(\mathbf{b})\left({ }^{210} \mathrm{Po} /{ }^{210} \mathrm{~Pb}\right)$ in the gas phase versus magma residence time in the degassing reservoir according to the new model (plain lines) and according the model of Gauthier et al. [15] (dashed lines). Curves for several values of transfer time $\theta(0,1 \mathrm{~h}, 1$, 5 and 30 days) are drawn. Fixed parameters of the model are $\alpha=5 \mathrm{wt} . \%, f=1, \epsilon_{\mathrm{Pb}}=1.5 \%, \epsilon_{\mathrm{Bi}}=36 \%$ et $\epsilon_{\mathrm{Po}}=100 \%$.

Radioactive disequilibrium $\left({ }^{222} \mathrm{Rn} /{ }^{210} \mathrm{~Pb}\right.$ ) in the gas phase (not shown in Figure 4) upon exsolution $(\theta=0)$ dramatically increases with the residence time and can reach values as high as 1000 for residence 
times up to 100 days. Therefore, huge ${ }^{222} \mathrm{Rn}$ enrichments can be generated because of the difference of gas-melt partitioning coefficients between ${ }^{222} \mathrm{Rn}$ and its non-volatile precursor ${ }^{226} \mathrm{Ra}$. This prediction confirms the potential for important ${ }^{210} \mathrm{~Pb}$ ingrowth in the gas phase during its transfer.

Radioactive disequilibria $\left({ }^{210} \mathrm{Bi} /{ }^{210} \mathrm{~Pb}\right)$ and $\left({ }^{210} \mathrm{Po} /{ }^{210} \mathrm{~Pb}\right)$ (Figure 4$)$ in the gas phase the time of exsolution $(\theta=0)$ are identical between the two models, which was expected since ${ }^{222} \mathrm{Rn}$ has no time to decay within gas bubbles. The observed trends have been explained by Gauthier et al. [15]: $\left({ }^{210} \mathrm{Po} /{ }^{210} \mathrm{~Pb}\right)_{G}$ significantly increases with the residence time $\tau$, as a result of ${ }^{210} \mathrm{Po}$ regeneration in the liquid phase of the degassing reservoir; $\left({ }^{210} \mathrm{Bi} /{ }^{210} \mathrm{~Pb}\right)_{G}$ also increases with $\tau$ but at a slower rate. This is because the regeneration of ${ }^{210} \mathrm{Bi}$ by ${ }^{210} \mathrm{~Pb}$ decay in the liquid phase is not as important, which is due to the smaller difference of volatility between $\mathrm{Pb}$ and $\mathrm{Bi}$ than between $\mathrm{Pb}$ and $\mathrm{Po}$.

In contrast, when the escape time of gases is not negligible $(\theta>0)$, our model predicts significantly lower (by a factor 2 or more) values than those derived from Gauthier et al. [15]. $\left({ }^{210} \mathrm{Bi} /{ }^{210} \mathrm{~Pb}\right.$ ) activity ratio in the gas phase, as computed with the former model ([15], dashed lines in Figure 4a), decreases with increasing values of $\theta$ from 0 to 30 days owing to the short half-life of ${ }^{210} \mathrm{Bi}$. In about one month (6 times ${ }^{210} \mathrm{Bi}$ half-life of 5.01 days), ${ }^{210} \mathrm{Bi}$ is back to equilibrium with its parent ${ }^{210} \mathrm{~Pb}$, leading to an activity ratio of 1 . Our model suggests, however, that low values of $\left({ }^{210} \mathrm{Bi} /{ }^{210} \mathrm{~Pb}\right)_{G}$ can be produced for gas transfer time $\theta$ as short as a few days (solid lines, Figure 4a). This feature is explained by both the radioactive decay of ${ }^{210} \mathrm{Bi}$ according to its own half-life and the radioactive decay of ${ }^{222} \mathrm{Rn}$ within gas bubbles, which produces new ${ }^{210} \mathrm{~Pb}$ atoms. Accordingly, $\left({ }^{210} \mathrm{Bi}\right)_{\mathrm{G}}^{\theta}$ decreases for increasing values of $\theta$ while $\left({ }^{210} \mathrm{~Pb}\right)_{G}^{\theta}$ increases, leading to a faster decrease in the $\left({ }^{210} \mathrm{Bi} /{ }^{210} \mathrm{~Pb}\right)_{G}$ activity ratio. However, for longer transfer times (e.g., $\theta=30$ days), the two models produce again similar values close to the equilibrium ratio of 1 , as expected since both ${ }^{222} \mathrm{Rn}$ and ${ }^{210} \mathrm{Bi}$ have similar half-lives (3.82 days and 5.01 days, respectively). In other words, the most important difference between the two models happens for magma residence times $\tau$ higher than a few hundred days (significant regeneration of ${ }^{222} \mathrm{Rn}$ from ${ }^{226} \mathrm{Ra}$ in the degassing melt and subsequent radon enrichments in the gas phase) and gas transfer times $\theta$ shorter than a few days (significant ${ }^{222} \mathrm{Rn}$-driven production of novel atoms of ${ }^{210} \mathrm{~Pb}$ within gas bubbles with limited return of ${ }^{210} \mathrm{Bi}$ to radioactive equilibrium).

The same conclusion can be drawn regarding $\left({ }^{210} \mathrm{Po} /{ }^{210} \mathrm{~Pb}\right)_{G}$ activity ratios (Figure $4 \mathrm{~b}$ ). The effect of ${ }^{222} \mathrm{Rn}$ decay is even more pronounced since the decrease in $\left({ }^{210} \mathrm{Po}\right)_{\mathrm{G}}^{\theta}$ according to the half-life of ${ }^{210} \mathrm{Po}$ (138.4 days) is rather limited for short transfer times $\theta$. The radioactive decay of ${ }^{222} \mathrm{Rn}$ thus strongly controls the magnitude of ${ }^{210} \mathrm{~Pb}^{210} \mathrm{Po}$ radioactive disequilibria. For instance, for values of $\tau$ higher than 150 days, it can be seen that our degassing model produces $\left({ }^{210} \mathrm{Po} /{ }^{210} \mathrm{~Pb}\right)_{G}$ activity ratios at $\theta=1 \mathrm{~h}$ lower than those derived from Gauthier et al. [15] for $\theta=30$ days.

These results highlight the need for taking ${ }^{222} \mathrm{Rn}$ into account in dynamic degassing models. They also suggest that activity ratios in the gas phase as low as those measured in the plume of Mount Etna could be explained and modelled within this novel theoretical framework.

\section{Model Application}

It can be seen from Equations (11) and (14) that the model relies on two variables (i.e., the magma residence time $\tau$ and the gas transfer time $\theta$ ) as well as on five parameters:

- the volatile weight fraction involved in the degassing process $\alpha$,

- the fraction $f$ of degassed radon [37],

- the emanation coefficients $\epsilon$ of lead, bismuth and polonium (ultimately converted to gas-melt partitioning coefficients using Equation (6)).

Provided that the five parameters $\alpha, f, \epsilon_{\mathrm{Pb}}, \epsilon_{\mathrm{Bi}}$, and $\epsilon_{\mathrm{Po}}$ can be estimated independently and the two $\left({ }^{210} \mathrm{Po} /{ }^{210} \mathrm{~Pb}\right)_{G}$ and $\left({ }^{210} \mathrm{Bi} /{ }^{210} \mathrm{~Pb}\right)_{G}$ activity ratios in the gas phase can be measured precisely, both $\tau$ and $\theta$ values can then be accurately determined from the model. However, these conditions are not necessarily met due to large analytical uncertainties on activity ratios and a broad range of values for emanation coefficients. Therefore, the mathematical system appears underdetermined. 
To overcome this difficulty, we choose to use a range of likely values for the five input parameters and the two variables, based on previous results for Mount Etna and other basaltic systems. Then, we perform a Monte Carlo type simulation (see Section 4.2 for more details on the methodology) in order to determine which $\tau$ and $\theta$ values (or ranges of values) can explain activity ratios measured in the volcanic plume.

\subsection{Estimation of Input Paramaters}

\subsubsection{Volatile Weight Fraction $\alpha$}

The volatile weight fraction involved in the degassing process, $\alpha$, controls the relative proportion of gas and liquid phases coexisting in the degassing reservoir. It is a key parameter because gaseous trace element compounds are too scarce to nucleate gas bubbles in the melt, and they need a major volatile species (e.g., $\mathrm{H}_{2} \mathrm{O}$ ) to be flushed out of the magma [40]. The total volatile content of magmas is often estimated from volatile concentrations in melt inclusions trapped in crystals, assuming that these melt inclusions represent the deep undegassed magma. In magmatic systems, the main volatile species are, by decreasing order of importance, $\mathrm{H}_{2} \mathrm{O}, \mathrm{CO}_{2}, \mathrm{~S}$-species (mostly $\mathrm{SO}_{2}$ in basaltic systems), $\mathrm{HCl}$ and HF. Since these species have different solubilities in basalts, the depth-related pressure of inclusion entrapment has to be considered in order to derive a reliable total volatile content dissolved in the magma prior to degassing. At Mount Etna, olivine-hosted melt inclusions have been studied for long by different authors e.g., [41,42]. Their studies yield to close estimates of the volatile weight fraction $\alpha$ in the range $4-5 \mathrm{wt} . \%$. Such high volatile content appears to be characteristic of alkali-rich basaltic magmas like those of Etna [42]. In other geodynamical settings and especially at non-arc-related volcanoes, the total amount of dissolved volatile usually is much lower [2]. Nevertheless, it must be pointed out that the model still applies to these volcanoes, provided that $\alpha$ is carefully quantified.

\subsubsection{Fraction of Degassed Radon $f$}

The fraction of radon released upon magma degassing, $f$, is a major parameter of our model since it directly controls the magnitude of ${ }^{222} \mathrm{Rn}$ enrichments in the gas phase and, subsequently, the radioactive ingrowth of ${ }^{210} \mathrm{~Pb}$ within gas bubbles. Very few data exist in the literature about radon degassing from basaltic magmas. Nevertheless, analyses of freshly erupted basalts and andesites [27,43] provide evidence for almost thorough radon degassing from erupting magmas. Further experimental studies [40,44] confirm that radon is entirely flushed out of mafic magmas upon degassing, provided that a major gas species can act as a carrier. Although $f$ is most likely close to 1 at Etna, we use here a conservative estimate with $f$ varying between $90 \%$ and $100 \%$.

4.1.3. Volatilities of Lead, Bismuth and Polonium (Emanation Coefficients $\epsilon$ and Gas-Melt Partitioning Coefficients $D$ )

The volatility of lead and bismuth is not so easy to assess since both elements are much less volatile than radon. Lead and bismuth, as many other heavy metals, are not volatile in their pure metallic form but are rather engaged in chemical compounds (halides or sulfates) that can be degassed at magma temperature. However, near-equilibrium values of $\left({ }^{226} \mathrm{Ra} /{ }^{210} \mathrm{~Pb}\right)$ in erupted basaltic lavas ([35], and references therein) including Etnean basalts [45] suggest a minimal loss of ${ }^{210} \mathrm{~Pb}$ upon degassing and hence an emanation coefficient of lead of a few percents at most (1.5\% according to [14]). Mather [26] computed a "volatility coefficient" (equivalent to a gas-melt partitioning coefficient) for lead using gas and lava data from Mount Etna, which is as low as 0.13. Using Equation (6) with $\alpha=5 \mathrm{wt} . \%$, it corresponds to an emanation coefficient of $0.7 \%$. Therefore, we take $\epsilon_{\mathrm{Pb}}$ between 0.7 and $1.5 \%$ (corresponding to $D_{\mathrm{Pb}}$ values in the range $0.13-0.37$ ). 
When the emanation coefficient of lead is known, Pennisi et al. [17] suggested to obtain $\epsilon_{\mathrm{Bi}}$ by scaling bismuth to lead with the ratio of their common stable isotopes according to:

$$
\epsilon_{\mathrm{Bi}}=\left(1+\frac{1-\epsilon_{\mathrm{Pb}}}{\epsilon_{\mathrm{Pb}}} \frac{[\mathrm{Pb}]_{G}}{[\mathrm{~Pb}]_{L}} \frac{[\mathrm{Bi}]_{L}}{[\mathrm{Bi}]_{G}}\right)
$$

where $[X]$ represents concentration in lava (subscript L) and volcanic plume (subscript G). Using trace element analyses in both Etnean gas and erupted lava from Aiuppa et al. [32], we estimate $\epsilon_{\mathrm{Bi}}=36 \%$. This value is in fair agreement with other estimates found in the literature in the case of Mount Etna: $45 \%$ in Lambert et al. [14]; $20 \%$ in Pennisi et al. [17]. A large range of variation of $\epsilon_{\mathrm{Bi}}(20-45 \%)$ is thus chosen according to these few estimates. It corresponds to partitioning coefficients $D_{\mathrm{Bi}}$ in the range 4.75-19.6.

Almost nothing is known on the geochemical behaviour of polonium, apart from its affinity for the vapour phase. Because polonium has no stable isotope, its emanation coefficient cannot be calculated in the same way as bismuth. The value of $\epsilon_{\text {Po }}$ must therefore be determined from analyses of freshly erupted basaltic lavas e.g., [27-30]. All these studies show that erupting lavas are almost entirely Po-depleted and concur to a value of $\epsilon_{\text {Po }}$ close to 100\%. At Etna, a similar method [22] suggested more incomplete polonium degassing, leading to an emanation coefficient as low as $80 \%$. We thus use a range of $\epsilon_{\text {Po }}$ between $80 \%$ and $100 \%$, which is $D_{\text {Po }}>100$.

\subsection{Inversion of the Model}

\subsubsection{Methodology}

In order to assess whether the presented model can explain the measured values in the plume of Mount Etna, the following system of two equations has to be solved for $\tau$ and $\theta$ :

$$
\left\{\begin{array}{l}
\left(\frac{{ }^{210} \mathrm{Bi}}{{ }^{210} \mathrm{~Pb}}\right)_{G}^{\tau, \theta}=7.5 \pm 0.4, \\
\left(\frac{{ }^{210} \mathrm{Po}}{{ }^{210} \mathrm{~Pb}}\right)_{G}^{\tau, \theta}=42 \pm 6 .
\end{array}\right.
$$

We prefer not to solve this system of theoretical equations for $\tau$ and $\theta$ since this would imply to know precisely each of the five parameters of the model ( $\alpha, f$, and emanation coefficients) while they are not so well constrained. Instead, we prefer a Monte Carlo type simulation according to the following procedure:

- $\quad$ each parameter (see Table 2) is chosen randomly in its range of variation according to an uniform law.

- $\quad$ the residence time $\tau$ and the transfer time $\theta$ are also chosen randomly (between 0 and 5000 days for $\tau$, and between 0 and 15 days for $\theta$ ). The upper limit for $\tau$ is in agreement with the order of magnitude of Mount Etna magma residence time in shallow reservoirs: a few tens of years in Condomines et al. [45], one year in Armienti et al. [46]. The upper limit for $\theta$ is coherent with maximum estimates of the gas phase transfer time at Mount Etna [14].

- $\quad$ radioactive disequilibria in the gas phase are computed according to the model equations.

- if the computed values match the measured ones, then the set of parameters and the dynamic variables $(\tau$ and $\theta)$ are stored in a database.

- $\quad$ these operations are repeated until a statistically relevant database (here 10,000 elements) is built. If enough combinations of parameters are simulated, the parameter space is sampled without any important gap.

The database is finally analysed using histograms or scatter plots (Figures 5-7). 
Table 2. Ranges of value regarding each parameter for the simulation.

\begin{tabular}{ccc}
\hline Parameter & Range & References \\
\hline$\alpha($ wt. $\%)$ & $4-5$ & Métrich et al. [41], Spilliaert et al. [42] \\
$f$ & $0.9-1$ & Gill et al. [27], Gauthier et al. [40], Sato and Sato [43], Sato et al. [44] \\
$\epsilon_{\mathrm{Pb}}(\%)$ & $0.7-1.5$ & Lambert et al. [14], Mather [26] \\
$\epsilon_{\mathrm{Bi}}(\%)$ & $20-45$ & Lambert et al. [14], Pennisi et al. [17] \\
$\epsilon_{\mathrm{Po}}(\%)$ & $80-100$ & Le Cloarec et al. [22], Gill et al. [27], Reagan et al. [28], Girard et al. [30] \\
\hline
\end{tabular}

\subsubsection{Discussion of Results and Implications for Magma Dynamics at Mount Etna}

The model can explain the radioactive disequilibria measured in Mount Etna plume for many combinations of parameters. Regarding input parameters (Figure 5), flat distributions observed for $\alpha$ and $f$ means that, in the frame of our model, all values tested are equally compatible with the measured disequilibria. It thus appears that these two parameters have a rather limited influence on the mathematical modelling when they vary across the assigned range of values. The same conclusion holds true for $\epsilon_{\mathrm{Pb}}$ although a significantly higher frequency is observed towards the highest values $\left(1.1 \%<\epsilon_{\mathrm{Pb}}<1.5 \%\right)$. In contrast, non-flat distributions indicate that the capability of the model to reproduce measured disequilibria is very sensitive to both $\epsilon_{\mathrm{Bi}}$ and $\epsilon_{\mathrm{Po}}$ values, which are not constrained precisely enough. There is no satisfactory combination of parameters for $\epsilon_{\mathrm{Bi}}<34 \%$ and $\epsilon_{\mathrm{Po}}>88 \%$. It suggests that (i) $\epsilon_{\mathrm{Bi}}$ might be as high as values reported by Lambert et al. [14] (45\%); (ii) polonium degassing efficiency might be as low as reported by Le Cloarec et al. [22] (80\%).
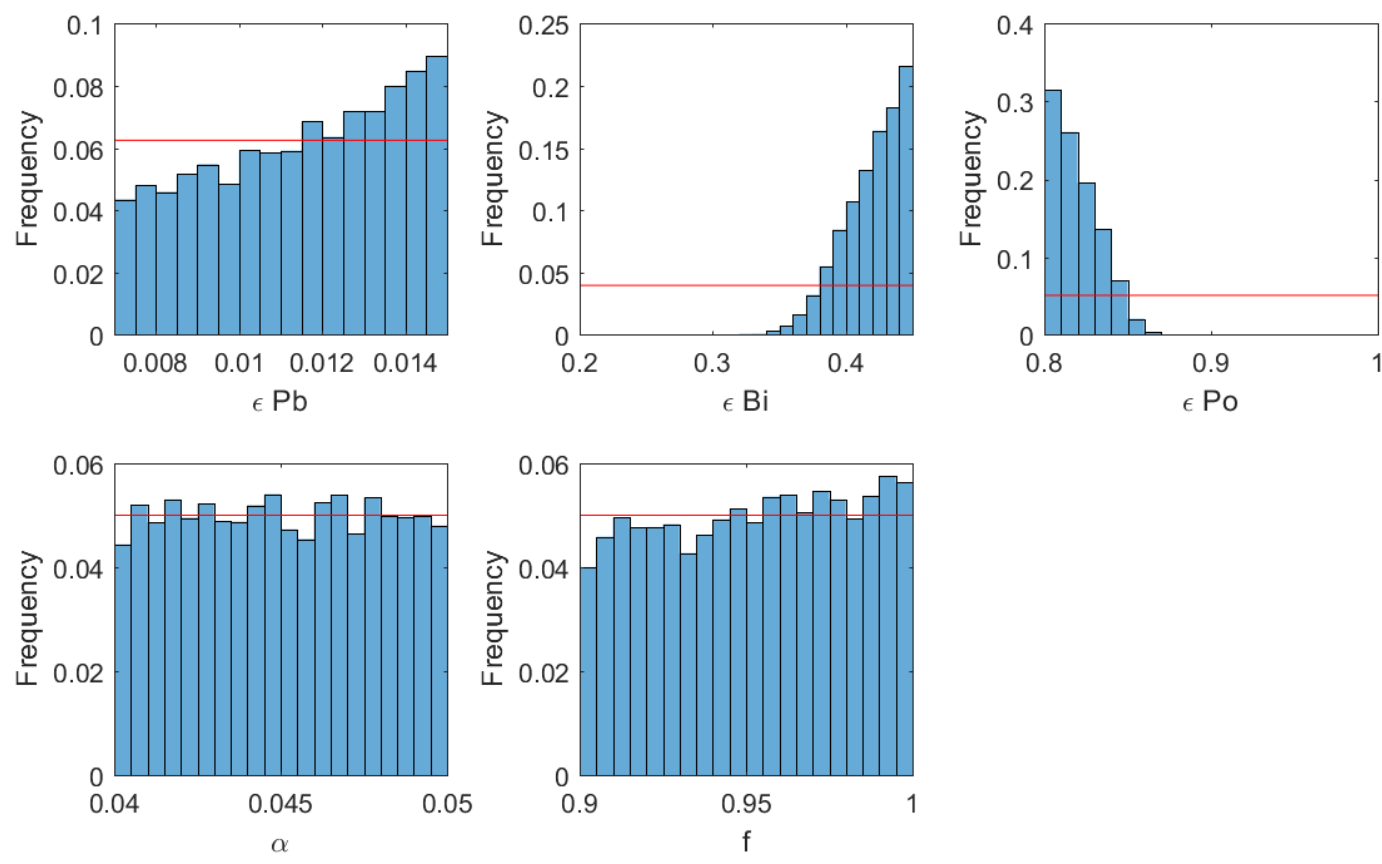

Figure 5. Histograms of the model parameters $\left(\alpha, f, \epsilon_{\mathrm{Pb}}, \epsilon_{\mathrm{Bi}}, \epsilon_{\mathrm{Po}}\right)$ for which the model can explain the measurements. The horizontal bar represents the uniform law used to generate random values. This line corresponds to the theoretical histogram that would be obtained for a parameter having no influence on the production of simulated results matching measured activity ratios. Its frequency is not relevant in itself and is merely equal to the reciprocal of the number of bars in the histogram. 

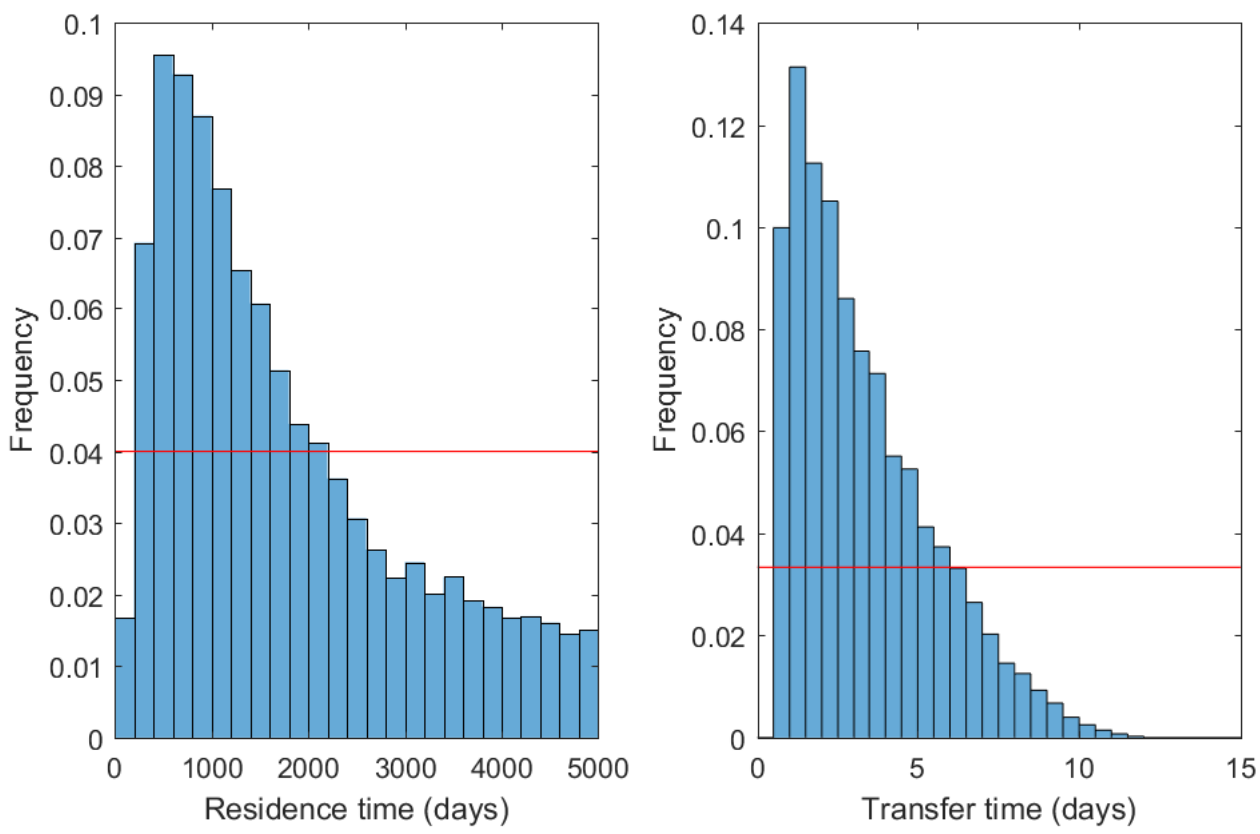

Figure 6. Histograms of the dynamic parameters $(\tau$ and $\theta$ ) for which the model can explain the measurements. The horizontal bar represents the uniform law used to generate random values. See the caption of Figure 5 for further details.

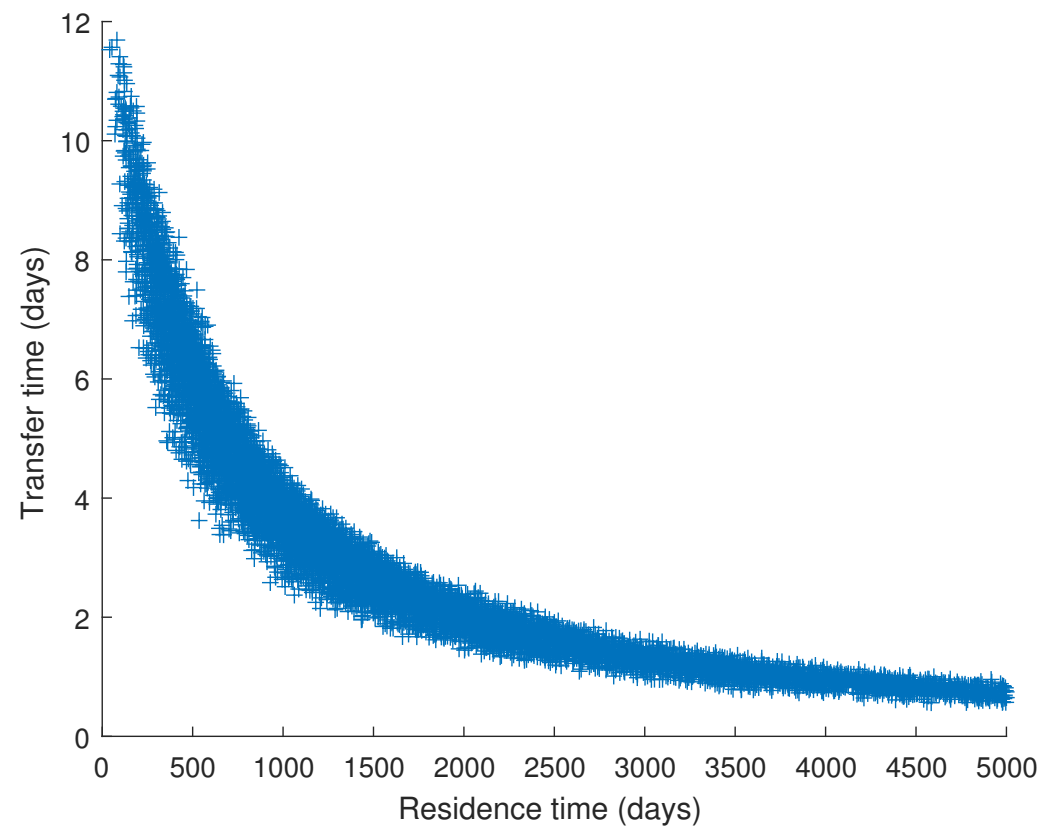

Figure 7. Scatter plot of the dynamic parameters $(\tau$ versus $\theta$ ) for which the model can explain the measurements.

The histogram of the residence time values peaks between 500 and 1000 days but also extends to the maximum value of 5000 days (Figure 6). The histogram of the transfer time also peaks at low values (between 1 and 3 days) but shows instead that the computation produces no satisfactory results for $\theta>12$ days. From a statistical perspective, it is thus most likely that measured radioactive disequilibria in the gas plume of Mount Etna are best explained by dynamical parameters in the range 500-1000 days and 1-3 days for $\tau$ and $\theta$, respectively. Nevertheless, all satisfactory dynamic parameters 
align roughly on an hyperbole (Figure 7), which is logical since residence time and transfer time tend to act on disequilibria in opposed ways (disequilibria increasing with $\tau$ and decreasing with $\theta$ ).

These two end-members have different geological implications. Because magma residence time is given by the relation $\tau=M / \phi_{0}$, higher residence times are associated with larger degassing reservoirs. At open conduit volcanoes, the transfer time of gas is likely dependent on the depth where gas exsolution takes places. Thus, longer transfer times likely correspond to deeper degassing reservoirs. The first above-mentioned end-member (high $\tau$ and low $\theta$ ) is therefore associated with a large degassing reservoir stored at shallow depth. Such scenario appears unlikely since large magma bodies $\left(>1 \mathrm{~km}^{3}\right)$ at very shallow depth $(<1 \mathrm{~km})$ would tend to erupt immediately. The second end-member (low $\tau$ and high $\theta$ ) is instead associated with a smaller magma reservoir seated at a greater depth. Again, this appears unlikely as small volumes $\left(<10^{6} \mathrm{~m}^{3}\right)$ of magma stored at several kilometres depth would not be able to drive the present-day eruptive activity of Mount Etna.

An estimate of the magma flux entering the degassing reservoir $\phi_{0}$ can be calculated from the mean $\mathrm{SO}_{2}$ flux measured during the field campaign and the eruptive stage from 12 May to 16 May $(5200 \mathrm{t} / \mathrm{d})$. Scaled to the sulfur content of Etnean basalts $(0.3 \mathrm{wt} . \%$ in [42]), considering complete $\mathrm{SO}_{2}$ degassing and a magma density of $2700 \mathrm{~kg} / \mathrm{m}^{3}$, we find $\phi_{0}=8.7 \times 10^{8} \mathrm{~kg} / \mathrm{d}=3.2 \times 10^{5} \mathrm{~m}^{3} / \mathrm{d}$. Owing to the definition of the magma residence time, the volume of the degassing reservoir is merely given by $V=\phi_{0} \tau$. Our estimate of $\phi_{0}$ thus yields a volume of $0.15-0.30 \mathrm{~km}^{3}$ for a degassing reservoir having a residence time of 500-1000 days (peak values in Figure 6). A residence time of 5000 days (highest value tested in our simulation; Figure 6) would correspond to a reservoir volume of $1.5 \mathrm{~km}^{3}$.

These estimates can be compared to the erupted volumes of lava during recent major eruptive events at Mount Etna. From 1995 to 2005, a cumulative volume of ca. $230 \times 10^{6} \mathrm{~m}^{3}$ (dense-rock equivalent magma) has been erupted during major lava flow events [47]. These events are thought to be responsible for the complete discharge of the shallow (and degassing) plumbing system of the volcano [47] whose maximum storage capacity is thus $0.23 \mathrm{~km}^{3}$. This value compares well with previous estimates of the shallow plumbing system of Etna derived from degassing budgets during the previous eruptive cycle $\left(0.3-0.6 \mathrm{~km}^{3}\right.$, [4] ) or geochemical considerations $\left(0.5 \mathrm{~km}^{3}\right.$, [45]). The $0.15-0.30$ $\mathrm{km}^{3}$ estimate derived from radioactive disequilibria in volcanic gases for $\tau=500-1000$ days thus appears more realistic than the $1.5 \mathrm{~km}^{3}$ end-member obtained for longer residence times.

The transfer time of gases produced by the simulation falls in the range 1-12 days. Considering a likely value of $\tau$ between 500 and 1000 days, the range for $\theta$ is reduced to 2-7 days (Figure 7). These values of a few days are in good agreement with previous determinations made for Etna [14], but they are significantly higher than those determined for the shallow $(<100 \mathrm{~m})$ degassing system of Stromboli where gases escape the magmatic system in one hour or less [15]. Such gas transfer time cannot be easily quantified as a depth of degassing since the bubble ascent rate through the whole feeding system of Etna is mostly unknown. However, by analogy with Stromboli volcano which produces slightly more differentiated basaltic magmas, a transfer time of a few days could be tentatively related to an exsolution depth of a few kilometres at most. The bottom of the feeding system of Etna is often envisaged at a depth of about $5 \mathrm{~km}$ below sea level [47]. It thus appears that effective degassing-driven radionuclide fractionation takes place within the upper part of the magmatic system.

\section{Conclusions}

We carried out in 2015 a new survey of ${ }^{210} \mathrm{~Pb}^{210} \mathrm{Bi}^{210} \mathrm{Po}$ radioactive disequilibria in the plume of Mount Etna. Measured activity ratios in the gas phase are in good agreement with values previously reported in the literature for the volcano. However, they can not be explained by existing theoretical models accounting for radionuclide degassing.

The presence of ${ }^{222} \mathrm{Rn}$, ignored in previous models, in the exsolved magmatic gas phase is thought to play a major role on the ${ }^{210} \mathrm{~Pb}^{-210} \mathrm{Bi}^{210} \mathrm{Po}$ systematics by producing ${ }^{210} \mathrm{~Pb}$ excesses in the gas phase during its transfer towards the surface. Here, this contribution has been modelled theoretically and it 
appears to produce radioactive disequilibria that can be twice as low as those predicted by the former degassing model of Gauthier et al. [15].

When applied to the case of Mount Etna, this novel degassing model can reproduce measured activity ratios. It strengthens the validity of our approach by underscoring the importance of ${ }^{222} \mathrm{Rn}$ enrichments in producing ${ }^{210} \mathrm{~Pb}$ excesses in the gas phase. Precise quantification of magma dynamics (i.e., magma residence time $\tau$ and gas transfer time $\theta$ ) beneath active volcanoes through the use of our degassing model necessitates a sharp characterisation of the different input parameters, especially radionuclide emanation coefficients $\epsilon$. Nevertheless, using a range of published estimates for $\epsilon$ values, we found that measured activity ratios in the plume of Mount Etna are most likely explained by a magma residence time in the degassing reservoir of 500-1000 days and a transfer time no longer than seven days. These figures correspond to a volume of degassing magma of about $0.15 \mathrm{~km}^{3}$ with an exsolution depth of no more than $5 \mathrm{~km}$ bsl. This volume of magma and its location in the shallowest part of the volcanic edifice suggests that most of the degassing process takes place within the shallow feeding system of Etna whose dynamics controls eruptive activity at the summit craters.

Further studies should now be devoted to direct measurements of ${ }^{222} \mathrm{Rn}$ activity in diluted volcanic plumes in order to provide evidence of radon enrichments. It will have further implications, notably in better deciphering ${ }^{210} \mathrm{~Pb}^{210} \mathrm{Bi}^{210} \mathrm{Po}$ desequilibria in volcanic gases, including at basaltic volcanoes from other geodynamical settings.

Acknowledgments: This work was initiated in the frame of the MEDiterranean SUpersite Volcanoes (MED-SUV) project (funding from the European Union Seventh Framework Programme (FP7) under Grant agreement No. 308665). It was also part of EtnaPlumeLab-Radioactive Aerosols (EPL-RADIO) project funded by ENVRIplus project (EU Horizon 2020 research and innovation programme 498, grant agreement No. 654182). Département de Géosciences, Ecole Normale Supérieure, Laboratoire Magmas et Volcans (through the ANR DegazMag) and Observatoire de Physique du Globe de Clermont-Ferrand provided additional funding and support and are all acknowledged. This paper benefitted from comments from two anonymous reviewers who are greatly acknowledged. This is ClerVolc contribution No. 282.

Author Contributions: All authors equally contributed to data acquisition in the field either through direct sampling of volcanic aerosols, remote-sensing measurements, or logistic support. Luca Terray and Pierre-J. Gauthier conceived the study and designed the degassing model; sample analyses were carried out by Pierre-J. Gauthier and numerical simulations were ran by Luca Terray Furthermore, Luca Terray wrote the paper with the contribution of all authors.

Conflicts of Interest: The authors declare no conflict of interest.

\section{Appendix A}

Activities of ${ }^{210} \mathrm{Bi}$ and ${ }^{210} \mathrm{Po}$ in the gas phase are determined by following the procedure described in Section 3.2.2. Corresponding expressions are reproduced hereafter:

$$
\begin{aligned}
& \left({ }^{210} \mathrm{Bi}\right)_{G}=\left[\frac{\lambda_{\mathrm{Bi}}}{D_{\mathrm{Pb}}} \times \frac{\lambda_{\mathrm{Pb}} \frac{1-f}{1-\alpha}+\frac{1}{\tau}}{\frac{\lambda_{\mathrm{Pb}}}{D_{\mathrm{Pb}}}+\left(\alpha+\frac{1-\alpha}{D_{\mathrm{Pb}}}\right) \frac{1}{\tau}}(A)_{0}+\frac{1}{\tau}(A)_{0}\right] \\
& \times\left[\frac{\lambda_{\mathrm{Bi}}}{D_{\mathrm{Bi}}}+\left(\alpha+\frac{1-\alpha}{D_{\mathrm{Bi}}}\right) \frac{1}{\tau}\right]^{-1}, \\
& \left({ }^{210} \mathrm{Po}\right)_{G}=\left[\frac{\lambda_{\mathrm{Po}}}{D_{\mathrm{Bi}}} \frac{\frac{\lambda_{\mathrm{Bi}}}{D_{\mathrm{Pb}}} \times \frac{\lambda_{\mathrm{Pb}} \frac{1-f}{1-\alpha}+\frac{1}{\tau}}{\frac{\lambda_{\mathrm{Pb}}}{D_{\mathrm{Pb}}}+\left(\alpha+\frac{1-\alpha}{D_{\mathrm{Pb}}}\right) \frac{1}{\tau}}(A)_{0}+\frac{1}{\tau}(A)_{0}}{\frac{\lambda_{\mathrm{Bi}}}{D_{\mathrm{Bi}}}+\left(\alpha+\frac{1-\alpha}{D_{\mathrm{Bi}}}\right) \frac{1}{\tau}}+\frac{1}{\tau}(A)_{0}\right] \\
& \times\left[\frac{\lambda_{\mathrm{Po}}}{D_{\mathrm{Po}}}+\left(\alpha+\frac{1-\alpha}{D_{\mathrm{Po}}}\right) \frac{1}{\tau}\right]^{-1} .
\end{aligned}
$$




\section{Appendix B}

The system of equations describing the evolution in time of the activities in a decay chain is often referred to as Bateman equations. The solution of Bateman equations can be written using matrices [39]. This compact formalism is much more convenient to implement in a numeric code. Bateman equations solution is given by Equation (14). Two matrices ( $M$ and its inverse matrix $M^{-1}$ ) appear in the equation. These matrices are equal to:

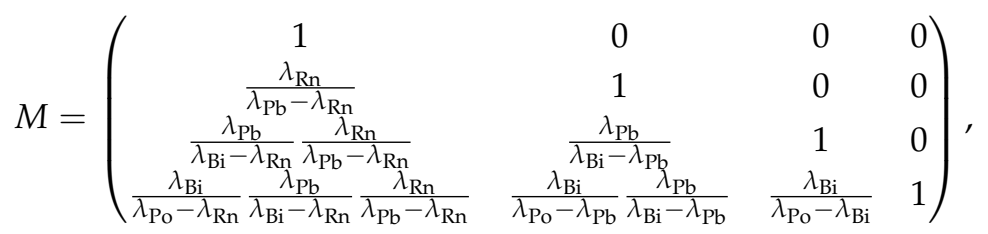

$$
\begin{aligned}
& M^{-1}=\left(\begin{array}{cccc}
1 & 0 & 0 & 0 \\
\frac{\lambda_{\mathrm{Rn}}}{\lambda_{\mathrm{Rn}}-\lambda_{\mathrm{Pb}}} & 1 & 0 & 0 \\
\frac{\lambda_{\mathrm{Rn}}}{\lambda_{\mathrm{Rn}}-\lambda_{\mathrm{Bi}}} \lambda_{\mathrm{Pb}}-\lambda_{\mathrm{Bi}} & \frac{\lambda_{\mathrm{Pb}}}{\lambda_{\mathrm{Pb}}-\lambda_{\mathrm{Bi}}} & 1 & 0 \\
\frac{\lambda_{\mathrm{Rn}}}{\lambda_{\mathrm{Rn}}-\lambda_{\mathrm{Po}}} \frac{\lambda_{\mathrm{Pb}}}{\lambda_{\mathrm{Pb}}-\lambda_{\mathrm{Po}}} \frac{\lambda_{\mathrm{Bi}}-\lambda_{\mathrm{Po}}}{\lambda_{\mathrm{Bab}}} & \frac{\lambda_{\mathrm{Pb}}-\lambda_{\mathrm{Po}}}{\lambda_{\mathrm{Bi}}-\lambda_{\mathrm{Po}}} & \frac{\lambda_{\mathrm{Bi}}}{\lambda_{\mathrm{Bi}}-\lambda_{\mathrm{Po}}} & 1
\end{array}\right),
\end{aligned}
$$

where $\lambda_{\mathrm{Rn}}, \lambda_{\mathrm{Pb}}, \lambda_{\mathrm{Bi}}$ and $\lambda_{\mathrm{Po}}$ are the radioactive decay constants of ${ }^{222} \mathrm{Rn},{ }^{210} \mathrm{~Pb},{ }^{210} \mathrm{Bi}$ and ${ }^{210} \mathrm{Po}$, respectively.

\section{References}

1. Caltabiano, T.; Burton, M.; Giammanco, S.; Allard, P.; Bruno, N.; Mure, F.; Romano, R. Volcanic gas emissions from the summit craters and flanks of Mt. Etna, 1987-2000. In Mt. Etna: Volcano Laboratory; Wiley: Hoboken, NJ, USA, 2004; pp. 111-128.

2. Wallace, P.J. Volatiles in subduction zone magmas: Concentrations and fluxes based on melt inclusion and volcanic gas data. J. Volcanol. Geotherm. Res. 2005, 140, 217-240.

3. Shinohara, H. Excess degassing from volcanoes and its role on eruptive and intrusive activity. Rev. Geophys. 2008, 46, doi:10.1029/2007RG000244.

4. Allard, P. Endogenous magma degassing and storage at Mount Etna. Geophys. Res. Lett. 1997, 24, 2219-2222.

5. Bonaccorso, A.; Bonforte, A.; Currenti, G.; Negro, C.D.; Stefano, A.D.; Greco, F. Magma storage, eruptive activity and flank instability: Inferences from ground deformation and gravity changes during the 1993-2000 recharging of Mt. Etna volcano. J. Volcanol. Geotherm. Res. 2011, 200, 245-254.

6. Sharma, K.; Blake, S.; Self, S.; Krueger, A.J. $\mathrm{SO}_{2}$ emissions from basaltic eruptions, and the excess sulfur issue. Geophys. Res. Lett. 2004, 31, L13612, doi:10.1029/2004GL019688.

7. Steffke, A.M.; Harris, A.J.; Burton, M.; Caltabiano, T.; Salerno, G.G. Coupled use of COSPEC and satellite measurements to define the volumetric balance during effusive eruptions at Mt. Etna, Italy. J. Volcanol. Geotherm. Res. 2011, 205, 47-53.

8. Schiano, P.; Clocchiatti, R.; Ottolini, L.; Busa, T. Transition of Mount Etna lavas from a mantle-plume to an island-arc magmatic source. Nature 2001, 412, 900-904.

9. Kazahaya, K.; Shinohara, H.; Saito, G. Excessive degassing of Izu-Oshima volcano: Magma convection in a conduit. Bull. Volcanol. 1994, 56, 207-216.

10. Stevenson, D.S.; Blake, S. Modelling the dynamics and thermodynamics of volcanic degassing. Bull. Volcanol. 1998, 60, 307-317.

11. Beckett, F.; Burton, M.; Mader, H.; Phillips, J.; Polacci, M.; Rust, A.; Witham, F. Conduit convection driving persistent degassing at basaltic volcanoes. J. Volcanol. Geotherm. Res. 2014, 283, $19-35$.

12. Ferlito, C.; Coltorti, M.; Lanzafame, G.; Giacomoni, P.P. The volatile flushing triggers eruptions at open conduit volcanoes: Evidence from Mount Etna volcano (Italy). Lithos 2014, 184, 447-455.

13. Moretti, R.; Métrich, N.; Arienzo, I.; Renzo, V.D.; Aiuppa, A.; Allard, P. Degassing vs. eruptive styles at Mt. Etna volcano (Sicily, Italy). Part I: Volatile stocking, gas fluxing, and the shift from low-energy to highly explosive basaltic eruptions. Chem. Geol. 2017, doi:10.1016/j.chemgeo.2017.09.017. 
14. Lambert, G.; Le Cloarec, M.F.; Ardouin, B.; Le Roulley, J.C. Volcanic emission of radionuclides and magma dynamics. Earth Planet. Sci. Lett. 1985, 76, 185-192.

15. Gauthier, P.J.; Le Cloarec, M.F.; Condomines, M. Degassing processes at Stromboli volcano inferred from short-lived disequilibria $\left({ }^{210} \mathrm{~Pb}-{ }^{210} \mathrm{Bi}_{-}{ }^{210} \mathrm{Po}\right)$ in volcanic gases. J. Volcanol. Geotherm. Res. 2000, 102, 1-19.

16. Lambert, G.; Bristeau, P.; Polian, G. Emission and enrichments of radon daughters from Etna volcano magma. Geophys. Res. Lett. 1976, 3, 724-726.

17. Pennisi, M.; Le Cloarec, M.F.; Lambert, G.; Le Roulley, J.C. Fractionation of metals in volcanic emissions. Earth Planet. Sci. Lett. 1988, 88, 284-288.

18. Le Cloarec, M.F.; Pennisi, M.; Ardouin, B.; Le Roulley, J.C.; Lambert, G. Relationship between gases and volcanic activity of Mount Etna in 1986. J. Geophys. Res. Solid Earth 1988, 93, 4477-4484.

19. Le Cloarec, M.F.; Pennisi, M. Radionuclides and sulfur content in Mount Etna plume in 1983-1995: New constraints on the magma feeding system. J. Volcanol. Geotherm. Res. 2001, 108, 141-155.

20. Allard, P.; Aiuppa, A.; Bani, P.; Métrich, N.; Bertagnini, A.; Gauthier, P.J.; Shinohara, H.; Sawyer, G.; Parello, F.; Bagnato, E.; et al. Prodigious emission rates and magma degassing budget of major, trace and radioactive volatile species from Ambrym basaltic volcano, Vanuatu island Arc. J. Volcanol. Geotherm. Res. 2016, $322,119-143$.

21. Gauthier, P.J.; Sigmarsson, O.; Gouhier, M.; Haddadi, B.; Moune, S. Elevated gas flux and trace metal degassing from the 2014-2015 fissure eruption at the Bárðarbunga volcanic system, Iceland. J. Geophys. Res. Solid Earth 2016, 121, 1610-1630.

22. Le Cloarec, M.F.; Lambert, G.; Le Guern, F.; Ardouin, B. Echanges de matériaux volatils entre phase solide, liquide et gazeuse au cours de l'éruption de l'Etna de 1983. Comptes-Rendus des Séances de l'Académie des Sciences. Série 2, Mécanique-Physique, Chimie, Sciences de l'univers, Sciences de la terre 1984, 298, 805-808. (In French)

23. Le Cloarec, M.F.; Lambert, G.; Ardouin, B. Isotopic enrichment of ${ }^{210} \mathrm{~Pb}$ in gaseous emission from Mount Etna (Sicily). Chem. Geol. 1988, 70, 128.

24. Behncke, B.; Branca, S.; Corsaro, R.A.; Beni, E.D.; Miraglia, L.; Proietti, C. The 2011-2012 summit activity of Mount Etna: Birth, growth and products of the new SE crater. J. Volcanol. Geotherm. Res. 2014, 270, $10-21$.

25. Geryes, T.; Monsanglant-Louvet, C. Determination of correction factors for alpha activity measurements in the environment (conditions of high dust loading). Radiat. Prot. Dosim. 2010, 144, 659-662.

26. Mather, T.A. Volcanoes and the environment: Lessons for understanding Earth's past and future from studies of present-day volcanic emissions. J. Volcanol. Geotherm. Res. 2015, 304, 160-179.

27. Gill, J.; Williams, R.; Bruland, K. Eruption of basalt and andesite lava degasses ${ }^{222} \mathrm{Rn}$ and ${ }^{210} \mathrm{Po}$. Geophys. Res. Lett. 1985, 12, 17-20.

28. Reagan, M.; Tepley, F.J.; Gill, J.B.; Wortel, M.; Hartman, B. Rapid time scales of basalt to andesite differentiation at Anatahan volcano, Mariana Islands. J. Volcanol. Geotherm. Res. 2005, 146, 171-183.

29. Sigmarsson, O.; Condomines, M.; Gauthier, P.J. Excess ${ }^{210}$ Po in 2010 Eyjafjallajökull tephra (Iceland): Evidence for pre-eruptive gas accumulation. Earth Planet. Sci. Lett. 2015, 427, 66-73.

30. Girard, G.; Reagan, M.K.; Sims, K.W.W.; Thornber, C.R.; Waters, C.L.; Phillips, E.H. ${ }^{238} \mathrm{U}-{ }^{230} \mathrm{Th}-{ }^{226} \mathrm{Ra}-{ }^{210} \mathrm{~Pb}-{ }^{210} \mathrm{Po}$ Disequilibria Constraints on Magma Generation, Ascent, and Degassing during the Ongoing Eruption of Kīlauea. J. Petrol. 2017, 58, 1199-1226.

31. Gauthier, P.J.; Le Cloarec, M.F. Variability of alkali and heavy metal fluxes released by Mt. Etna volcano, Sicily, between 1991 and 1995. J. Volcanol. Geotherm. Res. 1998, 81, 311-326.

32. Aiuppa, A.; Dongarrà, G.; Valenza, M.; Federico, C.; Pecoraino, G. Degassing of trace volatile metals during the 2001 eruption of Etna. In Volcanism and the Earth's Atmosphere; Wiley: Hoboken, NJ, USA, 2003; pp. 41-54.

33. Kayzar, T.M.; Cooper, K.M.; Reagan, M.K.; Kent, A.J. Gas transport model for the magmatic system at Mount Pinatubo, Philippines: Insights from $\left({ }^{210} \mathrm{~Pb}\right) /\left({ }^{226} \mathrm{Ra}\right)$. J. Volcanol. Geotherm. Res. 2009, 181, 124-140.

34. Condomines, M.; Sigmarsson, O.; Gauthier, P. A simple model of ${ }^{222} \mathrm{Rn}$ accumulation leading to ${ }^{210} \mathrm{~Pb}$ excesses in volcanic rocks. Earth Planet. Sci. Lett. 2010, 293, 331-338.

35. Berlo, K.; Turner, S. ${ }^{210} \mathrm{~Pb}-{ }^{226} \mathrm{Ra}$ disequilibria in volcanic rocks. Earth Planet. Sci. Lett. 2010, 296, $155-164$.

36. Reagan, M.; Turner, S.; Handley, H.; Turner, M.; Beier, C.; Caulfield, J.; Peate, D. ${ }^{210} \mathrm{~Pb}-{ }^{226} \mathrm{Ra}$ disequilibria in young gas-laden magmas. Sci. Rep. 2017, 7, 45186. 
37. Gauthier, P.J.; Condomines, M. ${ }^{210} \mathrm{~Pb}-{ }^{226} \mathrm{Ra}$ radioactive disequilibria in recent lavas and radon degassing: Inferences on the magma chamber dynamics at Stromboli and Merapi volcanoes. Earth Planet. Sci. Lett. 1999, 172, 111-126.

38. Bateman, $\mathrm{H}$. The solution of a system of differential equations occurring in the theory of radioactive transformations. Proc. Camb. Philos. Soc. 1910, 15, 423-427.

39. Moral, L.; Pacheco, A. Algebraic approach to the radioactive decay equations. Am. J. Phys. 2003, 71, 684-686.

40. Gauthier, P.J.; Condomines, M.; Hammouda, T. An experimental investigation of radon diffusion in an anhydrous andesitic melt at atmospheric pressure: Implications for radon degassing from erupting magmas. Geochim. Cosmochim. Acta 1999, 63, 645-656.

41. Métrich, N.; Allard, P.; Spilliaert, N.; Andronico, D.; Burton, M. 2001 flank eruption of the alkali- and volatile-rich primitive basalt responsible for Mount Etna's evolution in the last three decades. Earth Planet. Sci. Lett. 2004, 228, 1-17.

42. Spilliaert, N.; Métrich, N.; Allard, P. S-Cl-F degassing pattern of water-rich alkali basalt: Modelling and relationship with eruption styles on Mount Etna volcano. Earth Planet. Sci. Lett. 2006, 248, 772-786.

43. Sato, K.; Sato, J. Estimation of gas-releasing efficiency of erupting magma from ${ }^{226} \mathrm{Ra}-{ }^{222} \mathrm{Rn}$ disequilibrium. Nature 1977, 266, 439-440.

44. Sato, K.; Kaneoka, I.; Sato, J. Rare-gas releasing experiments and Rn degassing from erupting magma. Geochem. J. 1980, 14, 91-94.

45. Condomines, M.; Tanguy, J.C.; Michaud, V. Magma dynamics at Mt Etna: Constraints from U-Th-Ra-Pb radioactive disequilibria and Sr isotopes in historical lavas. Earth Planet. Sci. Lett. 1995, 132, $25-41$.

46. Armienti, P.; Pareschi, M.; Innocenti, F.; Pompilio, M. Effects of magma storage and ascent on the kinetics of crystal growth. Contrib. Mineral. Petrol. 1994, 115, 402-414.

47. Allard, P.; Behncke, B.; D'Amico, S.; Neri, M.; Gambino, S. Mount Etna 1993-2005: Anatomy of an evolving eruptive cycle. Earth-Sci. Rev. 2006, 78, 85-114.

(C) 2018 by the authors. Licensee MDPI, Basel, Switzerland. This article is an open access article distributed under the terms and conditions of the Creative Commons Attribution (CC BY) license (http:/ / creativecommons.org/licenses/by/4.0/). 